\title{
Principles of KYoto and Emissions TRAdiNG SYSTEMS: A PRIMER FOR ENERGY LAWYERS
}

\author{
BRIAN Evans*
}

The Kyoto Protocol defines new emissions standards to be met by the international community in respect of greenhouse gases. the aim of which is to curb the present irend of actverse climate change. The specific responses of ratifying governments 10 bring aboul the desired changes will significantly impact citizenry and indusiry alike.

This arficle addresses the issues surrounding emissions trading systems as market-based policy instruments that may ultimately contribute to Canada's legislative response to the Kyoto standards. Central to this question is the need to familiarize legal practitioners with the implications of climate change and the range of policy responses available to government in the context of emissions trading systems. The author examines responses open to the governments of Canada and Albersa through a review of the international reaction to climate change. the role of emissions irading in environmental regulation generally and the anticipated use of emissions srading to comply with the Kyoto Protocol in the furure. The author presents an indepth analysis of the principles underlying the design of domestic emissions trading systems, of the legislative authority surrounding their implementation and of the need for affected businesses to strategically plan for ensuing changes. The author concludes that while Canada has not yet adopted a policy on domestic emissions trading systems in respect of the Kyoto Protocol, the potential impact of emission standards on domestic sources is pronounced, meriting an inspection of the design features that may form a part of such trading schemes.
Le Protocole de Kyoto ésablir la norme des émissions à eflet de serre que la communauté internationale doir respecter. Ie but étant de freiner la tendance actuelle des changements climatiques. Les mesures prises spécifiquement par les gouvernements qui ont ratifie ce protocole dans le but d'opérer les changements désirés auront une incidence considérable sur les ciloyens et l'industrie.

Cet article porte sur les questions relatives aux systèmes d'ëchange de droits d'émissions en tant qu'instruments de politique axée sur les conditions du marche qui, en définitive, pewvent servir de réponse législative du Canada aux normes de Kyoto. Au caur de cette question. il y a cependant le besoin pour les hommes de loi de se familiariser avec les implications de ces changements climatiques ef la gamme des réponses d'ordre politique que le gouvernement peut donner dans le contexte des systèmes d'échange de droits d'émissions. L'auteur examine les réponses ouvertes aux gouvernements du Canada et de I'Alberta en étudiant la riaction imternationale aux changements climatiques. au röle de l'échange de droits d'émissions dans le domaine de la réglementation environnementale en général et $\dot{a}$ l'usage anticipé de l'echange de ces droits en vue de se conformer au Protocole de Kyoto. Lauteur prisente une analyse en profondeur des principes sous-jacents à la conception des systèmes d'échange de droits d'émissions intérieurs, de l'autorité législative relarive à leur mise en auvre et du besoin pour les entreprises concernées de planifier de mantère stratégique les changements qui s'imposemt. $L$ 'auteur conclut qu'alors que le Canada n'a pas encore adopté de politique sur les systèmes d'échange de drotts d'emissions intérieurs relativement au Protocole de Kyoto. L'incidence éveniwelle sur les sources interieures est certes réelle et mérite que la conception des éléments qui font partie de ces projets d'échange soil reviue.

\section{TABLE OF CONTENTS}

I. INTRODUCTION $\ldots \ldots \ldots \ldots \ldots \ldots \ldots \ldots \ldots \ldots \ldots \ldots \ldots, \ldots \ldots \ldots$

II. ThE "SCIEnCE" of Climate Change $\ldots \ldots \ldots \ldots \ldots \ldots \ldots \ldots, 170$ 
III. The International. Response to Climate Change -

THE KYOTO PROTOCOL . . . . . . . . . . . . . . . . . . . . . . . 172

IV. Principles of EMISSIONS TRAdING $\ldots \ldots \ldots \ldots \ldots \ldots \ldots \ldots \ldots \ldots \ldots \ldots$

A. Cap and Trade System $\ldots \ldots \ldots \ldots \ldots \ldots \ldots \ldots \ldots \ldots \ldots \ldots \ldots$

B. Credit Trading SYSTEM ...................... 179

C. NORTH AMERICAN EXPERIENCE WITH

Emissions Trading Programs .................. 180

V. PRINCIPLE DESIGN CONSIDERATIONS OF

Emissions Trading Systems $\ldots \ldots \ldots \ldots \ldots \ldots \ldots \ldots \ldots \ldots \ldots$

A. Coverage AND POINT OF IMPOSITION OF THE

Permit Trading System . . . . . . . . . . . . . . . . 187

B. SCOPE of THE EMISSIONS Trading Program $\ldots \ldots \ldots \ldots \ldots, 188$

C. MEASUREMENT, RePORTING AND VeRIFICATION

OF AllowANCES AND CREDITS $\ldots \ldots \ldots \ldots \ldots \ldots \ldots \ldots \ldots, 192$

D. Audit and Verification $\ldots \ldots \ldots \ldots \ldots \ldots \ldots \ldots \ldots \ldots$

E. MARKET InSTITUTIONS $\ldots \ldots \ldots \ldots \ldots \ldots \ldots \ldots \ldots \ldots \ldots \ldots$

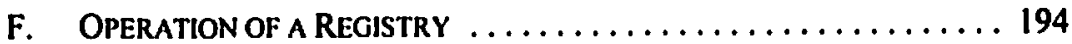

G. Trading Costs of Participants ................. 195

H. USAGE OF ALLOWANCES AND CREDITS $\ldots \ldots \ldots \ldots \ldots \ldots, 197$

I. METHOD Of Allocation OF AllowanCES

AND PERMITS $\ldots \ldots \ldots \ldots \ldots \ldots \ldots \ldots \ldots \ldots \ldots \ldots .200$

VI. CANADIAN LEGISLATIVE AUTHORITY FOR IMPLEMENTING

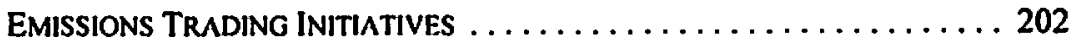

A. Federal Authority $\ldots \ldots \ldots \ldots \ldots \ldots \ldots \ldots \ldots \ldots \ldots \ldots$

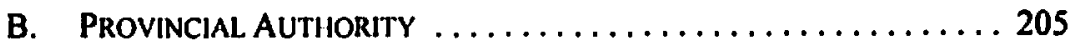

C. Federal Legislation Respecting

Emissions Trading .......................... 206

D. Provincial. Emissions Trading Legisi.ation $\ldots \ldots \ldots \ldots \ldots 207$

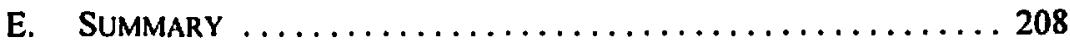

\section{INTRODUCTION}

This author's thesis, though perhaps naive, is that to many of us the debate surrounding climate change and the international and domestic response is somewhat amorphous - we know it is out there, we think it is bad, but we have difficulty getting a handle on what the real issues are and how our government's response will impact our businesses and our lives. Perhaps our governments and the media must assume some responsibility for our confusion as the issues, though complex, have become highly politicized both domestically and internationally and have not been particularly well communicated except among a relatively select group of stakeholders. The public's confusion is further compounded by the complexity of the issues and the speed with which developments are now occurring on a global and a domestic scale.

The purpose of this article is to provide legal practitioners with some theoretical background to the implications of climate change and the range of policy responses available to our governments as they relate to the use of market-based policy instruments. It is not the author's intention to debate the validity of the science of climate change nor the politics 
associated with our government's response whether internationally or domestically. That role is better left to our politicians and to those in the industry who are charged with responsibility for ensuring that the industry's voice is heard in the debate.

While Canada has now ratified the Kyoto Prorocol, it remains to be seen whether overall ratification will be achieved in order to bring the Kyoto Protocol into effect. 'It is now also clear, however, that our largest trading partner, the United States, will not be ratifying the Kyoso Protocol. That position may have profound implications for Canada, Alberta and those involved in the energy sector.

It would be incorrect, however, to assume that because the United States has not elected to ratify the Kyoto Protocol, nothing is being done in that country to deal with the issue of climate change and in particular, the effect of greenhouse gas (GHG) emissions. In many respects, the United States has pioneered the use of market-based policy instruments in the environmental arena. It is widely accepted that the implementation of international and domestic emissions trading systems will be significant weapons in our arsenal to effect absolute reductions in GHGs in the most economically efficient manner possible.

This article will briefly explore: the scientific underpinnings of climate change; the collective response of the international community evidenced by the signing of the Kyoto Protocol; the basic principles of market-based environmental policy instruments and how they might play a role in Kyoto Protocol compliance or GHG emissions reductions generally; the role that emissions trading has played in environmental regulation in the past; the role that emissions trading is expected to play in other countries in the context of Kyoto Protocol compliance; the basic principles behind the design of a domestic emissions trading system; the design options available to our policy makers; the legislative authority for implementing a Canadian domestic or international emissions trading system; and the need for early strategic planning by corporations whose businesses will be impacted by the domestic response to climate change and by legal counsel who must consider the legal implications of the expected government response for their clients.

While this article will add little to the academic study of emissions trading, it is hoped that it will provide a useful context within which lawyers can begin to understand the principles of emissions trading and their potential effect on legal practice. Although there is not yet any definitive position as to whether a domestic emissions trading system will be implemented in Canada, nor is there yet any definite position as to the design features that will be reflected in a Canadian emissions trading system or systems, it is the author's position that it is not too soon for lawyers to begin to understand the range of features that may be incorporated into such a system or systems and to begin to take those features into account in their practice in anticipation of the implementation of such a system.

This article focuses on the potential policy responses of the governments of Canada and Alberta as they might rclate to the use of market-based policy instruments. While actions of 
other provincial governments may well become relevant to the Canadian energy industry, the author has chosen to limit the scope of this article to two jurisdictions. ${ }^{2}$ This article has drawn heavily on the voluminous material that has been produced by the National Round Table on the Environment and the Economy (NRTEE), the National Climate Change Process (NCCP) and the various position papers published by each of the governments of Canada and Alberta in an effort to narrow the likely emissions trading system options available to the governments in designing a Canadian system or systems. ${ }^{3}$

\section{The "SCience" of Climate Change}

Data suggests that concentrations of carbon dioxide or $\mathrm{CO}_{2}$ were essentially stable for the 10,000 years between the end of the last ice age and the beginning of the 19 th century. ${ }^{4} \mathrm{By}$ some estimates, concentrations of atmospheric $\mathrm{CO}_{2}$ have increased by approximately 30 percent since the beginning of the 19th century and are projected to at least double preindustrial levels by the end of the 21 st century without intervention. ${ }^{3}$ While considerable uncertainty exists as to the rate of change which might result from increased concentrations of GHGs in the atmosphere, computer modeling suggests that the average global surface temperature is likely to increase between 1.4 and 5.8 degrees Celsius by $2100 .^{6}$

Possible effects of a global temperature change of this magnitude could include rising sea levels, regional increases in extreme weather events, such as storms, heat waves, floods and drought and significant consequences for ecosystems and socioeconomic systems. In Canada, impacts are forecasted to include degradation of the sea ice and melting permafrost in the north, rising sea levels in the coastal areas resulting in coastal flooding, drought increases throughout the prairies, shifting tree lines, increased exposure to pest infestations, negative inpacts on water quantity and quality and possibly the spread of vector borne diseases. ${ }^{7}$

A cursory understanding of the science of climate change will provide some context and background to the rationale behind developing international initiatives to respond to climate

See the discussion in Part Vl of this article relating to potential jurisdictional issues related to Canadian emission trading systems.

NTREE is an independent advisory body sanctioned by Parliament lo pruvide decisions makers and the Canadian public with advice and recommendations regarding sustainable development. The members are appointed by the Prime Minister and are drawn from a broad range of sectors including business, labour, academia, environmental organizations and the First Nations. NTREE's website may be found at < www.nrtee-trnee.ca/>. The NCCP was established in carly 1998 by the federal, provincial and territorial ministers responsible for energy and the environment in an effort to establish an inclusive and collaborative response to the challenges posed by the Kyoto Protocol and the need to address climate change. The NCCP established 16 working groups comprised of experts from industry, academia, nongovernmental organizations and government that reviewed seven key sectors of the economy and eight strategic responses culminating in the publication of a National Implementation Strategy and the First National Business Plan. These documents and the website for the NCCP may be found at <www.necp.ca/NCCP>.

Canada, A Discussion Paper on Canada's Contribution to Addressing Climate Change. (OAlawa: Government of Canada, 2002) at 10, online: Government of Canada, Climate Change <www.climate change.gc.ca/english/publications/canadascontribution/Report051402/englishbook.pdi] [Climate Change Discussion Paper].

Ibid.

lbid.

Ibid. at $11-12$. 
change. When discussing the science of climate change, it must be recognized that there is considerable uncertainty in climate science, particularly with respect to the nature of localized climate changes and the determination of the rate of change. However, whatever one's views are with respect to the validity of the science of climate change, the apparent worldwide consensus of perceived change has created sufficient momentum to strongly influence the development of global environmental policy.

The earth's atmosphere has a natural ability to insulate the earth's surface from heat loss. It is this insulating function (the greenhouse effect) which prevents the earth from being a frozen planet incapable of supporting life. It has been theorized that "without the global warming process, the average temperature of the earth would be approximately $33^{\circ}$ Celsius colder then it is." ${ }^{8}$ The greenhouse effect is the result of the complex interplay among the absorption of radiation from the sun by GHGs, such as water vapor, carbon dioxide, methane and nitrous oxide, and the earth's land surfaces, biosphere and oceans. As the quantity of GHGs in the atmosphere increases, the greenhouse effect is more pronounced and temperature increases. Clearly the amount of GHGs in the atmosphere is impacted to a large degree by the amount of gases emitted into the atmosphere. The earth's land surfaces, biosphere and oceans impact the process by absorbing or retaining or emitting GHG at different phases in their cycles.

A process through which the earth's surfaces, biosphere and oceans can absorb or "sequester" carbon dioxide from the atmosphere is known as a carbon sink and may include forests, soils, peat, permafrost, ocean water and carbonate deposits in the deep ocean. Most of these carbon sinks are very large and very slow moving; human influence on these sinks is generally deemed fairly minimal, with the possible exception of soils and agriculture. Fossil fuels represent historic carbon sinks that are now "fossilized" into mineral form. Though $\mathrm{CO}_{2}$ or methane is sequestered in fossil fuels while in mineral form, they can be released back into the atmosphere when the fuels are released into the atmosphere and burned.

Forests are the most commonly referenced form of carbon sink. Plants and trees absorb carbon dioxide from the atmosphere via photosynthesis, release oxygen back into the atmosphere and retain the carbon component as the building block of plant fiber. Therefore. long lived, high biomass plants, such as trees and forests, represent effective carbon sinks as long as they are maintained.

The degree to which the positive impacts of carbon sinks can be utilized in an emissions trading context is still a matter of contentious debate at the Intergovernmental Panel on Climate Change (IPCC) and elsewhere. 


\section{The International Response to Climate Cilange - THE KYOTO PROTOCOL}

The United Nations Conference on the Human Environment held in Stockholm in 1972 was the first international meeting to identify human induced climate change as a pressing global issue.' In 1988, the United Nations Environment Program and the World Meteorological Organization established the IPCC to examine the status of climate change and its potential effects. The work of the IPCC resulted in the execution of the Uniled Nations Framework Convention on Climate Change ${ }^{10}$ by 154 nations at the 1992 United Nations Conference on Environment and Development in Rio de Janeiro (the Earth Summit). The stated goal of the UNFCCC was to stabilize atmospheric concentrations of GHGs within a time frame sufficient to allow ecosystems to naturally adapt to climate change so that serious impacts upon food production and global economic development might be minimized. ${ }^{11}$ To that end, those parties to the UNFCCC that were developed countries, agreed to stabilize their GHG emissions at 1990 levels by the year $2000 .^{12}$

Following the release of the IPCC's second assessment report, the parties to the UNFCCC concluded that the original commitments made towards stabilization were inadequate and agreed to negotiate the implementation of further reductions in the period after the year 2000 within some sort of legal framework. These negotiations ultimately resulted in the execution of the Kyoto Protocol at the third Conference of the Parties (COP3) in Kyoto, Japan, in December 1997.

The Kyoto Protocol is based on the principle that response to climate change requires common but differentiated commitments between certain developed countries, comprised mainly of the members of the Organization for Economic Co-Operation and Development (OECD) and eastern European industrialized countries (Annex B Parties), and developing nations (Non-Annex B Parties). ${ }^{13}$ The Kyoto Protocol also contains elements designed to encourage the development of domestic programs to address climate change in the developing countries and technology transfer to encourage the allocation of additional resources to developing countries. It is this aspect of the Kyoto Prolocol that lead some to conclude that the Kyoto Protocol is little more than an international system of wealth transfer from north to south.

Ibid. at Annex 2.

9 May 1992, 1771 U.N.T.S. 107 [UNFCCC].

National Implementation Sirategy, supra note 8 at Annex 2.

These parties are the 36 industrialized nations or economies in transition listed in Annex I of the UNFCCC. They are frequently referred to as the Annex I Parties.

The Annex $B$ Parties are comprised of 39 industrialized nations and economies in transition listed in Annex $B$ of the Kyoto Protocol. Annex B countries are subject to legally binding emission reduction obligations. There are distinctions between members of the Annex I parties and the Annex B parties. Belarussia is in Annex I but not in Annex B while Croatia, Liechtenstein, Monaco and Slovenia are in Annex B, but not Annex 1. While in practice Annex 1 of the UNFCCC and Annex $\mathbf{B}$ of the Kyoto Protocol are often used interchangeably, there are important distinctions. Strictly speaking, it is the Annex I countries that can invest in Joint Implementation and Clean Development projects and can host Joint Implementation projects (discussed further below) while it is the Non-Annex I parties that can host Clean Development Mechanism projects. This is true while it is the Annex B countries which have binding emissions reduction targets under the Kyoto Protocol. 
Article 3 of the Kyoto Protocol commits developed Annex B Parties to show demonstrable progress towards achieving an ultimate goal of reducing their absolute emissions of six GHGs by 5.2 percent below 1990 levels by the period 2008-2012 (the Commitment Period).

The Kyoto Protocol covers six GHGs. The three principal gases are $\mathrm{CO}_{2}$, methane or $\mathrm{C}_{4}$ and nitrous oxide or $\mathrm{NO}_{2}$. There are three additional engineered chemicals, which occur on a very limited basis: perfluorocarbons (PFC's), sulfur hexafluoride or $\mathrm{SF}_{6}$ and hydrofluorocarbons (HFCs).

An increasing amount of $\left[\mathrm{CO}_{2}\right]$ is being released by the burning of rossil fuels (coal, oil, and natural gas) for industrial purposes, transpontation, and the heating/cooling of buildings, as well as by deforestation. Methane [which is the primary constituent of natural gas] is being released from landfills, wastewater treatment, certain agricultural practices, as well as from grazing livestock... An increasing amount of nitrous oxide is being emitred into the atmosphere through the use of chemical fertilizers and the burning of fossil fuels... [PFCs, $\mathrm{SF}_{6}$ and $\mathrm{HFCs}$ ] are not naturally occurring but ... are generated in a variety of industrial processes. ${ }^{\text {is }}$

While these latter three gases are relatively more potent gases, they are emitted in such small quantities that their overall impact is currently small. ${ }^{\text {s }} \mathrm{A}$ mega tonne is a popular unit of measurement for GHGs. One mega tonne is equal to one thousand tonnes. One tonne is equal to one thousand kilograms. One tonne of $\mathrm{CO}_{2}$ would fill the inside of an ordinary house. ${ }^{16}$

The Global Warming Potential (GWP) is an index that compares the relative potential of the GHGs covered by the Kyoro Protocol to contribute to global warming. $\mathrm{CO}_{2}$ has been recognized as the main contributor to climate change and has been attributed a GWP potential of $1 .{ }^{17} \mathrm{CO}_{2}$ is the standard by which the other gases are measured. The impact of the other gases are compared to the impacts of $\mathrm{CO}_{2}$ and then referred to in terms of $\mathrm{CO}_{2}$ equivalents $\left(\mathrm{CO}_{2} \mathrm{e}\right)$. Methane, for example, has a GWP of 23. Accordingly, the impact of a release of one mega tonne of methane into the atmosphere would be equivalent to the release of 23 mega tonnes of $\mathrm{CO}_{2}$.

Although the Kyoto Protocol contemplates a total reduction in GHGs by 5.2 percent below 1990 levels during the Commitment Period, the reductions are not the same for all countries but depend upon the degree of economic development, population, climate and size of the country. ${ }^{18}$ Canada committed to cut its emissions by 6 percent below 1990 levels. Developing countries face no immediate reduction target.

To give developed countries flexibility in meeting their targets and to promote investment and clean technologies in developing countries, the Kyoto Protocol provides for the use of

Canada, Climate Change Plan for Canada, (Ottawa: Government of Canada. 2002) at 5, online: Government of Canada, Climate Change <mww.climatechange.gc.ca/plan_for_Canada/plan/pdf/full version.pdB [Climate Change Plan 2002].

"Glossary," online: C02e.com <www.co2e.com/common/glossary.asp\#200|8>.

Climate Change Plan 2002, supra note 14 at 45.

Canada, Government of Canada Action Plan 2000 on Climate Change, (Ottawa: Government of Canada, 2000) at 4, online: Government of Canada, Climate Change <www.climatechange.ge.ca/ english/publications/ap2000/Action_Plan_2000_en.pdis [Climate Change Plan for Canada].

1. The European Union has agreed to an internal burden sharing arrangement that allows the distribution of a single Kyoto Protocol Commitment among its 15 member states. 
three market-based emissions trading mechanisms: International Emissions Trading (IET), ${ }^{19}$ Joint Implementation $(\mathrm{JI})^{20}$ and Clean Development Mechanism (CDM) $)^{21}$ (collectively the Kyoto Flexibility Mechanisms).

IET allows Annex I parties to fulfill their overall emission reduction commitments by buying and selling emission reduction credits. Emissions trading under the Kyoto Protocol applies only to Annex I countries and will not officially commence until the Kyoto Protocol comes into force.

$\mathrm{Jl}$ is a mandated program under which GHG emissions reduction projects can be implemented jointly between two or more developed Annex I countries. JI applies only to nations with quantified emissions caps whose projects will ultimately generate emissions reduction allowances. While the actual transfer of allowances will not begin until 2008, specific projects have been launching since the late 1990s under the Activities Implemented Jointly program.

JI can be bilateral or multilateral. A bilateral project permits a developed country to negotiate the framework agreement to set the rules for crediting. In a multilateral project, investing countries make contributions to an independent fund. Other nations then propose $\mathrm{JI}$ projects in order to compete for the fund's resources. Proposed projects are evaluated for their emission reduction efficiency potential; other positive attributes are considered in the case of equally efficient projects. Each investor country receives an emissions credit proportional to its share of the project portfolio for the duration of the project. Project risks are also pooled within the fund with the investor countries being required to pay a corresponding insurance surcharge. The necessary emission reduction verification can be carried out either multilaterally or by private auditors.

CDM is intended to result in the generation of emissions reduction credits from projects undertaken in developing countries that are not subject to binding GHG emission caps under the Kyoto Protocol, which can then be applied by the sponsoring developed country against its domestic emissions in order to reduce its overall targets. Under CDM, investors from Annex I states receive Certified Emissions Reduction units (CERs) for the actual amount of GHG emissions reduction achieved, subject to host country agreement and the CDM Adaptation Charge. A key component of the CDM is the requirement of additionality. CERs generated under the CDM will only be recognized when the reductions of GHG emissions are additional to any that would occur in the absence of the certified project activity. The administrative costs of the mechanism and the final structure of certification and verification under $\mathrm{CDM}$ are still under discussion.

The Kyoto Flexibility Mechanisms were included at the insistence of certain developed countries as a means to maximize the cost-effective implementation of the Kyoto Protocol. As a consequence, the developed countries agreed to accept "more stringent [overall]

lbid., ant. 2. 
reduction commitments."22 While each of the three Kyoto Flexibility Mechanisms have different attributes, CDM is the only mechanism that contemplates an interplay between a developed and developing country and notably is the only mechanism that can result in tangible reduction credits between 2000 and the Commitment Period.

The Government of Canada has created the Clean Development Mechanism and Joint Implementation Office in the Department of Foreign Affairs and International Trade to assist Canadian companies wishing to access the market created under $\mathrm{Jl}$ and $\mathrm{CDM}$. The office negotiates bilateral agreements with host countries to secure project approvals as well as technical and funding assistance for various aspects of project implementation. The Government of Canada has committed to investing $\$ 15,000,000$ for projects that generate CERs through the World Bank Prototype Carbon Fund. ${ }^{23}$

As mentioned above, Canada's emission reduction commitment under the Kyoto Protocol requires emissions to be 6 percent below 1990 levels within the Commitment Period. There has been considerable debate surrounding the quantification of Canada's commitment, given the difficulties associated with accurately projecting Canada's business-as-usual (BAU) GHG emissions in the period between 1990 and the Commitment Period. The ultimate level of actual emissions will depend upon the rate of Canada's population and economic growth. ${ }^{24}$ It is, however, reasonably accepted that there will be a considerable gap between projected BAU emissions in the year 2010 and the 6 percent below 1990 levels committed to in the Kyoto Protocol. Based upon the Government of Canada's most recent estimate of the gap in Climate Change Plan for Canada, the gap between the anticipated BAU emission level and the 571 mega tonnes Kyolo Protocol target is approximately 240 mega tonnes of $\mathrm{CO}_{2} \mathrm{e}^{25}$ Suffice it to say for our purposes that the challenge for Canada in meeting its targets is considerable.

The entry into force of the Kyoto Protocol requires that 55 parties representing 55 percent of the 1990 Annex I CO $2 \mathrm{e}$ emissions ratify the Kyoto Protocol before it comes into effect. This provision was intended to ensure that participating Parties would not be legally bound to fulfill the terms of the Kyoto Protocol before their major trading partners were. The United States and Russia account for 53.5 percent of the Annex $\mathrm{I} \mathrm{CO}_{2} \mathrm{e}$ emissions, and therefore the Kyoto Protocol will not come into effect without ratification by one of these two countries. At present, 84 countries have signed (including Canada) and 110 countries have ratified, accepted, acceded or approved the Kyoro Prolocol, including 79 non-Annex I countries. ${ }^{26}$

Significantly, however, the United States has indicated its intention not to ratify the Kyoto Protocol. ${ }^{27}$ As a result, assuming ratification of the Kyoto Protocol, Canada and Mexico will

National Implementation Sirategy, supra note 8 at Annex 2.

Climate Change Plan 2002, supra note 14 at 43.

Canadian Association of Petroleum Producers (CAPP), Climate Change Policy Position, (Calgary: CAPP, 2002) at 2, online: CAPP <www.capp.ca/raw.asp?NOSTAT $=$ YES\&dt=PDF\&dn=40186>.

National implementation Sirategy, supra note 8 at Annex I.

United Nations, Kyoto Protocol: Status of Ratification, online: United Nations Framework Convention on Climate Change <unfecc.int/resource/kpstats.pdf>; United Nations, Kyoto Thermometer, online: United Nations Framework Convention on Climate Change <unfccc.int/resource/kpthermo.html>. John Barlow Weiner ef al. "International Legal Developments in Review" (2002) 36 Int'] Law. 319 at 322. 
be the only members of the North American Free Trade Agreemen ${ }^{23}$ that will be parties to the Kyoto Protocol - a situation that could have profound effects on Canada's international competitiveness. This is particularly so given that under current provisions Canada will be debited with all GHG emissions attributable to its natural gas production, processing and transportation notwithstanding that Canada exports approximately 60 percent of its natural gas production to the United States. ${ }^{29}$ While Canada will bear the burden of the emissions associated with the natural gas, the United States will enjoy the energy value of the resource without consequence for the actual emissions that will accrue when it is burned. Further, the United States will enjoy the environmental benefits and GHG emission reductions that will result from the utilization of natural gas as an alternative to much dirtier coal as an energy source for electrical production. As a result of this dichotomy, Canada is currently negotiating a credit to its emission levels equal to the $\mathrm{CO}_{2} \mathrm{e}$ of the natural gas it exports. ${ }^{30}$

Throughout the international climate change negotiations, several major issues resulted in the formation of various negotiating blocks - each reflecting significant differences in circumstances among the nations participating, including their geography, climate and political and economic structures and most notably, the degree of economic dependence upon the extraction, production and intensive use of fossil fuels and their vulnerability to the effects of climate change.

While the developed countries in Annex I bear the burden of the most immediate emissions reduction targets, emissions from developing countries are expected to rise exponentially with in the next twenty to thirty years such that "[d]eveloping country emissions are ... expected to account for nearly 50 percent of global industrial $\mathrm{CO}_{2}$ emissions by 2010 up from one third in 1996."

As a result, concern has been expressed in some of the developed countries that the lack of commitment being undertaken by the developing countries could seriously hamper the developed countries' international competitiveness. A related concern is that of carbon leakage. Carbon leakage occurs as a result of emission or energy intensive industries expanding existing facilities in or actually relocating facilities to countries which have not adopted emission reduction commitments, resulting in a significant loss of capital in the developed countries. It was concerns such as these that resulted in the United States refusing to ratify the Protocol. ${ }^{32}$

The Government of Canada tabled Climate Change Plan for Canada in 2000 outlining a three-step plan to meet its commitment of reducing Canadian GHG emissions by 240 mega

North American Free Trade Agreement Benveen the Government of Canada, she Government of Mexico and the Governmem of the United States, 17 December 1992, Can. T.S. 1994 No. 2, 32 1.L.M. 289 (entered into force 1 January 1994). 
tonnes of $\mathrm{CO}_{2}$ e by $2010 .^{33}$ The Climate Change Plan for Canada sets out a mixed approach involving five specific instruments:

(a) innovation and technology investments;

(b) infrastructure investments;

(c) partnership fund;

(d) targeted measures; and

(e) covenants and emissions trading by industry.

Unlike the Kyoto Protocol and the Climate Change Plan for Canada, which seek to reduce overall GHG emissions in absolute terms, the framework put forth by the Alberta government to deal with GHG reduction seeks to reduce the intensity of GHG emissions relative to the provincial gross domestic product. ${ }^{34}$ Alberta's goal is to reduce emissions in the province relative to gross domestic product by 50 percent below 1990 levels by 2020 . According to Alberta's Climate Change Action Plan, this will result in an absolute reduction in GHG emissions of approximately 60 million tonnes below business as usual levels. ${ }^{35}$ An interim reduction target has been set at 20 million tonnes lower than business as usual levels by $2010^{36}$ Like the Climate Change Plan for Canada, Alberla's Climate Change Action Plan also contemplates the development of an emissions trading system through the development of a definition of eligible GHG offsets, the establishment of a registry for $\mathrm{GHG}$ offsets and the implementation of initiatives to purchase real emissions reductions.

Whether or not the Kyoto Protocol ultimately becomes binding through ratification, it is likely that emissions trading will be a key domestic policy instrument to effect a reduction in emissions of GHGs or other pollutants. Given that it has been estimated that the domestic fossil fuel industries including pipelines are responsible for approximately 14.5 percent of the GHG emissions in Canada, it is imperative that these industries take steps to understand the principles underlying emissions trading systems so that they can incorporate climate change considerations into their corporate strategies, manage the resulting business risks and maintain an enhanced long term competitive advantage. ${ }^{37}$

Likewise, even though the precise details of the policy instruments likely to be used by the federal and provincial governments are not yet known, it is not too early for counsel to the industry to become familiar with the anticipated effects of potential command and control and market-based policy instruments which may be utilized in the future. These instruments will have a significant impact upon almost every facet of legal practice including energy, securities, insurance, banking, commercial, corporate governance and probably litigation.

Supra note 14.

Alberta, Albersans and Climase Change: Taking Action, (Edmonton: Government of Alberta, 2002). online: Alberta Environment <wnww3.gov.ab.ca/env/climate/actionplan/docs/takingaction.pdi> [Alberla's Climate Change Action Plan].

Ibid. at 10.

Ibid.

National Implementation Strategy, supra note 8 at Annex 3. 


\section{Principles of Emissions Trading}

Simplistically, emissions trading refers to the process whereby parties can buy or sell allowances or permits to emit regulated substances or credits granted by the regulating authorities for reductions achieved in emitting the regulated substance within a competitive market. In essence, the benefit that accrues from entitlement to an allowance, permit or credit becomes a commodity, which can be traded among market participants such as emitters, nongovernmental organizations, governments or environmental groups.

Emissions trading can significantly reduce the costs of controlling GHGs or other emissions, as it is based on the most basic of economic principles that where the relative costs of performing an activity differ among actors, there are potential gains to be made from trade. ${ }^{38}$ Though the design attributes of each emissions trading system, which has been utilized or is contemplated, varies with each system, there are two fundamental approaches to emissions trading systems: cap and trade systems; and credit trading systems.

\section{A. Cap and Trade System}

A cap and trade system is known as a closed system of emission trading that is created when a regulatory body sets a cap or limit on the absolute amount of emissions permitted from a source or group of sources. The cap is designed to reduce the impact of the emissions by setting the maximum at a lower level than historical emissions. Thus, the Kyoto Protocol has the effect of forming the basis of a cap or trade system by binding the Annex I Parties to a level of greenhouse emissions 5.2 percent below 1990 levels.

Once a cap has been determined, defined groups of emitters are authorized to emit a certain proportion of the total amount of available emissions. This can occur on either a national, sectoral or corporate level. Thus the Kyoto Protocol has allocated the total amount of available emissions among the Annex I countries. Each of these countries might likewise allocate its share of allowable emissions among its political subdivisions, its economic sectors or on a corporate basis. The allowable emissions would be allocated among the defined groups of emitters either gratis or via auctioning.

Emitters that successfully reduce their emissions below their allocated level may sell their unused allowances to other emitters whose emissions are exceeding their allocated allowance. Participants that emit substances beyond their allocated allowance and in excess of any additional allowances purchased from others would be severely penalized. Penalties can include requiring the plant owner to purchase the necessary allowances to bring the plant into compliance for that year at a significant multiple of the market value for those allowances, or reducing the plant's allocation of allowances for the upcoming year. The advantage of a cap and trade system is that because the penalties for non-compliance are so punitive, noncompliance is simply not an option at the practical business level. In other words, an emitter facing a potential non-compliance situation for one of its plants will not allow that plant to 
fall into non-compliance because, often for the same or less money than it would pay in penalties, it could make the necessary changes to bring the plant into compliance. This increases the likelihood that total emissions from all sources will not exceed the cap, as businesses will respond rationally to economic incentives.

This type of emissions trading system is particularly well-suited for an environment where emitters have different marginal costs of reducing their emissions. This is so whether we are referring to emitters on a national level or a micro level. Emitters with lower marginal costs of abatement will seek to implement technological or other changes in order to physically reduce their level of emissions. They may then be in a position to perhaps bank their unused allowances for future periods or sell those allowances to other emitters who have higher marginal costs of abatement. ${ }^{39}$ This way, the higher cost emitters have some flexibility in ensuring that they emit within their available allowances by purchasing additional allowances at a lower cost than they would have incurred had they undertaken physical measures to reduce their actual emissions.

\section{B. Credit Trading System}

Under a credit trading system, which is known as an open system, emitters could either voluntarily agree to limit their emissions to a certain level or the regulating authority might impose such a limit. Emitters that voluntarily reduce their emissions below the regulated or voluntarily assumed limit would receive credits for the amount of emissions not actually emitted as a result of their reduction activities. Those credits, once verified and registered, could be saved or banked and used to offset future emissions that exceed the regulated or agreed upon limit, or could be sold to other emitters who have been unable to maintain their levels of emissions within their applicable limits.

Unlike a closed cap and trade system, a credit trading system may not be as likely to ensure that the overall environmental objective of reduced emissions will occur, as the allocation of credits, while providing an incentive to reduce emissions, are not mandatory. In order for the credit trading system to be effective, it is essential that stringent criteria and monitoring is in place to ensure that reductions, which are to qualify for offsets or credits, are actually additional to BAU practices and result in a real reduction and not the result of some reduction that would have taken place in any event.

Emission trading is by no means a new concept. There is a mounting body of evidence which suggests that emissions trading works. For example, the well known Acid Rain Program in the United States is widely recognized as a highly successful sulphur dioxide emissions trading program that delivered large emissions reductions for a fraction of the originally predicted cost and has reduced the intensity of acid rainfall in the eastern and midwestern states in which it was implemented.

19 The ability to bank allowances for future use is an optional design feature of emissions trading systems and may not be available in every system. 


\section{North american Experience with Emissions Tanding Programs}

Traditional command and control environmental regulatory methods are relied on by the government or a governmental agency to set specific environmental standards and directives to be followed by emitters subject to the regulatory authority, as well as the penalties to which they would be subject in the event of non-compliance. These command and control structures have been criticized for being expensive, bureaucratic, overly rigid and stifling to innovation. ${ }^{40}$ In response to these criticisms, various jurisdictions in the United States and Canada have employed market-based environmental policy instruments in an effort to increase flexibility and cost-effectiveness by allowing the market to identify the lowest cost opportunities for reducing emissions of regulated substances.

In Annex 2 of its 1999 report, Canada's Options for a Domestic Green House Gas Emission Trading Program, NRTEE selected and reviewed several existing emissions trading programs. ${ }^{41}$ Several of these programs are outlined below.

\section{TRADING FOR THE LEAD CONTINT OF GASOLINE}

In 1982, the American Environmental Protection Agency (EPA) introduced a maximum lead content for leaded gasoline. Trading was introduced as part of the EPA's program to phase out leaded gasoline. As noted in Annex 2 of the NRTEE Options Report, participants could "create lead rights equal to the regulatory limit on the lead content of leaded gasoline multiplied by their leaded gasoline production during the calendar quarter less the actual quantity of lead used."'2 Lead rights could be sold to other market participants during the quarter in which they were created. In addition, the EPA allowed refiners and importers to bank lead credits and to withdraw those credits until the end of a fixed period.

In NRTEE's view, the lead credit trading program enabled the EPA to reduce the maximum lead content of gasoline much more rapidly than would have occurred under a program without trading where refiners would have needed additional time to adjust to new standards. While the voluntary lead credit trading program did not affect the overall volume of lead use, it was effective in assisting the industry to adapt to a new standard in a more economically efficient manner than would have occurred without trading. ${ }^{43}$

The trading system created in relation to the lead content in gasoline program is an example of a voluntary emissions trading program that works in conjunction with mandatory emission standards.

National Roundtable on the Environment and the Economy (NRTEE), The ABCs of Emissions Trading: An Overview, (Ottawa: NRTEE, 2002), online: NRTEE <unww.nrtec-trnee.ca/EmissionsTrading/ en/ABCs-EmissionsTrading-t.pdß

" National Roundtable on the Environment and the Economy (NRTEE), Canada's Options for a Domestic Greenhouse Gas Emission Trading Program. (Ottawa: NRTEE, 1999) at Annex 2, online: NRTEE < $m$ ww.nrtee-tmee.ca/Publications/PDF/Repon_Emissions-Options_E.pdP [NRTEE Option.s Report].

: Ibid. at 90

" For more detailed information, sec Annex 2 of the NRTEE Options Report, ibid. at 90-91. 


\section{OzOnE Depleting SubStances}

The Montreal Protocol came into force on I January 1989 and attempted to reduce the use of substances such as chlorofuorocarbons that destroy the stratospheric ozone layer. ${ }^{44}$ In Canada, ozone depleting substances were made subject to a system of "grandfathering." That is, consumption allowances were initially allocated among Canadian companies based upon their historical consumption patterns. The consumption allowances were allocated to Canadian companies in an amount equal to that company's share of Canada's consumption of that group of substances during a specified base year. Transfers of the allowances between companies have been permitted since 1993. With the exception of methyl bromide, allowances were issued to importers and producers.

With the small number of companies involved and the intense competition among them, very few transfers of allowances occurred. NRTEE suggests that this is probably because the competitive disadvantage that could arise by enabling the purchaser of the allowances to gain market share thereby outweighed the benefits that would have accrued to the seller in the form of revenue from the sale of the allowances. ${ }^{45}$

Methyl bromide allowances were introduced in 1995. Because there were only five importers of methyl bromide, there was considerable concern that they would be able to control the market in methyl bromide allowances. As a result, the allowances were issued to approximately 133 and-users or consumers. ${ }^{26}$

The Canadian trading system created in relation to ozone depleting substances is an example of a mandatory cap and trade system. It provided valuable lessons about the risk of allowance market manipulation when dealing with a narrow market and possible system design solutions.

\section{TITLE IV ACID RAIN PROGRAM}

Title IV of the 1990 amendments to the Clean $A i r A c r^{7}$ in the United States added to the Clean $\mathrm{Air} \mathrm{Act}^{48}$ a comprehensive market-based program for the control of sulphur dioxide $\left(\mathrm{SO}_{2}\right)$ emissions from coal-fired electrical utility power plants. The acid rain program is a typical downstream cap and trade emissions trading program which "is designed to achieve a 7.7 million metric tonne reduction in $\mathrm{SO}_{2}$ emissions from electric utilities between 1995 and 2010."49

The Clean Air Act identifies by name the affected units and sources subject to the program, along with their allowance allocation. It is noteworthy that Title IV expressly (entered into force I January 1989) [Montreal Protocol].

4' NRTEE Options Report. supra note 41 at 94.

4. For further information on trading programs in ozone-depleting substances in Canada and the United States, see ibid. at 93-95.

"Clean Air Act Amendments of 1990, Pub. L. No. 101-549, 104 Stat. 2399 at 2584 (1990).

4t 42 U.S.C. $\$ 740 \mathrm{I}(2000)$.

" NRTEE Options Report, supra note 41 at 95. 
provides that an allowance issued under the acid rain program is not a property right. This is an indication of the level of concern that legislators and regulators hold that the issue of allowances remain classified as a regulatory permit or authorization to emit noxious substances that may be subject to future regulatory amendments or revisions. This is of particular concern given the U.S. constitutional environment in which property rights are enshrined. $^{50}$

Though the aggregate number of $\mathrm{SO}_{2}$ allowances has been capped, specified amounts of allowances have been set aside for annual auctions, direct sales and incentives. Thus, new generators or facilities that opt into the acid rain program will be required to obtain allowances either through the EPA sales or from facilities with surplus allowances. Allowances were initially issued gratis and were allocated to individual units based on actual emissions in 1985, subject to certain adjustments. The Clean Air Act allows the owner or operalor of a unit that emits $\mathrm{SO}_{2}$ that is not subject to the acid rain program to opt into the program and thereby become eligible for an allocation of allowances.

The Acid Rain Program allowance market has been very active since the early 1990s. In the late 1990s, allowances were trading in a range of US $\$ 100$ to US $\$ 200$ per tonne."

Monitoring of emissions under the program was undertaken using tamper-proof continuous emission monitors (CEMs). Participants whose emissions exceed their allowances are heavily penalized by the imposition of automatic administrative penalties, which may exceed the current trading price for allowances by almost 20 times. In addition, participants are required to purchase allowances to make up for their over-emissions. Generally, the government's cost of administering the program and the transaction costs related to trades are reportedly relatively low..$^{22}$

The acid rain program has been extremely successful in reducing $\mathrm{SO}_{2}$ emissions from power plants beyond compliance with plant specific reduction requirements in an economically efficient manner.

\section{Regional Clean Air INITIATIVES Market}

In 1993, the South Coast Air Quality Management District (SCAQMD) established the Regional Clean Air Initiatives Market (RECLAIM). ${ }^{31}$ RECLAIM is intended to reduce emissions of $\mathrm{SO}_{2}$ and $\mathrm{NO}_{2}$ in the Los Angeles Basin through the capping of emissions and the allocation of allowances to sources of $\mathrm{SO}_{2}$ and $\mathrm{NO}_{2}$. This cap and trade allowance emissions trading program applies to approximately 330 facilities, which emit in excess of

Sandi M. Rudinstein, "Is Emission Trading Worth It?" John Hopkins Joumal of American Politics (February 2002), online: John Hopkins University, The Washington Centre <jhcourse.jhu.edu/ as $480661 />$.

NRTEE Options Report, supra nute 41 at 95.

Ibid.

In 1993 the South Coast Air Quality Management District established the Regional Clean Air Initiatives Market, referred to as "RECLAIM" in Regulation XX, 40 C.F.R. Part 70, App. A, enabled by 42 U.S.C. $\$ \$ 7501$ et seq. (Adopted 15 October 1993). 
3.6 tonnes per year. Each of those facilities receives an annual emissions allocation and an annual rate of reduction in emissions. ${ }^{54}$

Emissions allowances were issued gratis to participants on the basis of historic production levels and emission factors applicable to the type of facility. New and significantly modified facilities were required to obtain allowances to offset their emissions and were still subject to regulated technology standards. Allowable $\mathrm{NO}_{2}$ emissions from stationary sources were scheduled to decline from about 106 tonnes per day to 26 tonnes per day, and $\mathrm{SO}_{2}$ emissions were scheduled to reduce from 24 tonnes per day to 10 tonnes per day in 2003 . $^{35}$

Although each source received a specific allocation that represented its total emission reduction requirements, the specific control requirements and the timing of the reduction was under the control of the source. As a result, the source could shift emissions between various pieces of equipment under its overall facility allocation. In the alternative, if the source emitted less than its allocation, it was entitled to sell its RECLAIM credits to another source. There have been reportedly hundreds of transactions involving the transfer of credits under the RECLAIM program worth tens of millions of dollars since taking effect in 1994. ${ }^{56}$

The NRTEE noted that complaints have been made that the RECLAIM program was excessively generous in giving firms flexibility in determining historic production and emission levels that were the basis for allowance allocation resulting in allowable emissions that were higher than actual baseline year emissions. ${ }^{57}$

Notwithstanding disagreement as to whether RECLAIM's emission results represented an improvement over the original air quality plan, it was projected to save approximately $\$ 58$ million compared to the cost of traditional command and control measures. ${ }^{58}$

\section{Pilot Emissions Reduction Trading Program}

The Pilot Emissions Reduction Trading Program (PERT) project was established in Ontario in 1996 as a voluntary self-funded, non-profit multi-stakeholder organization made up of industrial organizations, governments, consultants and health and environmental organizations. ${ }^{59}$ Although the primary focus of the PERT process was $\mathrm{NO}_{2}$ and volatile organic compounds (VOCs) emissions in Southern Ontario, the participants were requested to track changes in emissions of all pollutants as a result of actions under PERT. It was

Ibid. at Rule 200.

3s U.S., U.S. Environmental Protection Agency (EPA), "EPA's Efforts to Reduce SO," (Washington: United States Government, 2002) online: EPA <www.epa.gov/air/urbanair/s02/effrtl. litml>.

5\%. South Coast Air Quality Management District (SCAQMD) "AQMD Governing Body Actions Summary"( 8 May 1998) online: SCAQMD <wiww.aqmi.gov/monthly/may 98 .html>.

NRTEE Options Report, supra note 41 at 96

lbid.

Pilot Emission Reduction Trading, Clean Air Mechanisms and the PERT Project: A Five Year Report, (Toronto: Pilot Emission Reduction Trading, 2000), online: Clean Ais Canada < www.cleanaircanada. org/upld_doe/cac_doc/CleanAirMechanisms.doc?. 
discovered that PERT had the ancillary effect of achieving significant reductions in $\mathrm{CO}_{2}$ emissions, which were emitted from the same sources as the $\mathrm{NO}_{2}$ and VOC emissions. ${ }^{60}$

Credit creation actions undertaken by the participants were documented in a protocol in a manner that described the actions implemented and the reductions achieved. That material was then reviewed to ensure that the reductions were real and surplus. Credits that were created could be used by participants in the program, subject to the rules of any subsequent emissions trading program that resulted from the pilot project, or could be banked and applied to meet other potential future regulatory obligations. Approval of a credit creation protocol by the PERT registration team did not validate the creation of the credits. That approval remained within the authority of the Ontario Ministry of the Environment. The results of the PERT review process, however, were made available to anyone wishing to purchase the credits created to assist the buyer with its due diligence respecting: confirmation of the existence of the emission reduction; whether the emission reduction claimed as a credit was truly surplus to a mandatory requirement; whether the emission reductions were additional; whether they were verifiable; and whether they were in fact owned by the seller of the credit. ${ }^{\circ}$

\section{GREenhouse Gas EMISSION REDUCtion TRADING}

In 1996, Environment Canada and the Greater Vancouver Regional District jointly funded a design study, the Greenhouse Gas Emission Reduction Trading Pilot (GERT) project, for an offset pilot project that targeted GHG emissions. ${ }^{62}$ The pilot project included representatives of several provincial, federal and local government agencies, the private sector, and labour and environmental groups including the Alberta Department of Energy and Environmental Protection. ${ }^{63}$

Industry participants were able to voluntarily bring forward for review proposed emissions reduction projects or trades that result in emissions reduction, avoidance or sequestration. The proposals were reviewed by the GERT technical committee to assess whether they met the criteria and rules established by GERT. Projects could be located within or outside Canada, but buyers and sellers of emission reduction credits were required to be Canadian. The pilot considered only projects where an emission reduction credit trade occurred. To be eligible for registration, the emissions reductions must have been real, measurable, verifiable and surplus as defined by GERT as follows:

NRTEE: Options Report, supra note 41 at 86 . Although the PERT program itself has expired, the membership formed Clean Nir Canada in order to continue to serve the same objectives as PERT and to serve as a forum for the review and registration of GHG emission reduction activities. The Clean Air Canada website is at <www.cleanaircanada.org/>.

i.) Ibid. at 88 .

$\therefore \quad$ lbid.

6. GERT Technical Committce, Greenhouse Gas Emission Reduction Trading Pilot (GERT): Final Report, (Regina: Greenhouse Gas Emission Trading Pilot Project, 2002) at 1, online: GERT <www. gert.org/Final/0208 10\%20GERT\%20Final\%20Report.dpf final_report.pdf?. 
1. Real: The project must result in a reduction in actual emissions, resulting from a specific and identifiable action or undertaking, net of any leakage of emissions to a third party or jurisdiction;

2. Measurable: The actual level of GHG emissions with the project in place and the level of GHG emissions in the reference case must be quantifiable;

3. Verifiable: The calculation methodology is acceptable, transparent and replicable and the raw data required to verify or audit the calculations must be available; and

4. Surplus: The emissions reduction is surplus if it represents a reduction that is not otherwise required by law either at the outset or at any time during the life of the Program. ${ }^{64}$

Emission reductions that satisfied GERT's criteria and reporting requirements were designated as registered emission reductions and recognized by the government partners in GERT. ${ }^{65}$

The GERT project expired on December 3I, 1999.

\section{Principal design Considerations of Emissions Trading Systems}

There are a number of considerations affecting the administrative and operational aspects of emissions trading systems that are common to different system designs and that must be considered and addressed. These issues relate to the coverage and point of imposition of the system; scope of the trading program; measurement reporting and verification of allowances and credits; costs of trading for participants; the use of allowances and credits; and the capability of the system to respond to changes in circumstances that affect it.

NRTEE initiated a project in the spring of 1998 to examine possible designs for a domestic emissions trading program for GHGs. The project was launched with a document that outlined 14 potential emissions trading programs and 16 different design issues that applied to multiple designs. From that report, nine issues were selected for more detailed analysis. ${ }^{66}$ As a result of that detailed work, five potential domestic GHG emissions trading programs were evaluated in more detail and described in the NRTEE Option Report. ${ }^{67}$

Subsequently, the Tradeable Permits Working Group (TPWG) of the National Climate Change Process (NCCP) undertook to explore the potential contribution of mandatory domestic emissions trading systems towards achieving a substantial reduction in greenhouse

is The government partners were Alberta Environment, BC Ministry of Energy and Mines, BC Ministry of Water, Land and Air Protection, Environment Canada. Natural Resources Canada. Manitoba Energy and Mines, Nova Scotia Natural Resources, Quebec Ministry of Natural Resources, Saskatchewan Industry and Resources and the Greater Vancouver Regional District.

4. Possible Designs for a Domestic Emissions Trading Program for Greenhouse Gase.r attached as Appendix I to the NRTEE Options Report, supra note 41 at $69-83$. 
emissions in Canada. The result of their efforts was the publication of their final report in April 2000 (the TPWG Options Report). ${ }^{68}$

While the TWPG utilized the NRTEE Options Report as a highly valuable resource, it had a slightly different focus and reached slightly different conclusions. Each of the reports, however, noted that any final determination as to the role of a domestic emissions trading program in Canada's efforts to meet its Kyoto Protocol commitments required substantially more research and analysis before any firm policy decisions could be made.

The TWPG properly recognized that two primary policy issues needed to be addressed that would have a significant impact on business, households, institutions and consumers in Canada:

(i) what emissions would be covered by the policy instruments; and

(ii) how the cost burden of the policies would be distributed..$^{69}$

Much of the TWPG Options Report was devoted to providing a discussion of various alternatives that may impact the political decision makers in setting the foregoing two policy issues.

The TWPG noted that there are important incidence and equity issues that ultimately affect how the economic burden of achieving desired emission reductions would likely be shared. ${ }^{70}$ By incidence the TWPG was referring to how the economic burden would be shared, while by equity the TWPG was referring to how the burden should be shared. The burden of achieving greenhouse emissions reductions will generally be shared among the following market participants:

\footnotetext{
people with ownership interests in firms whose production processes involve GHG emissions (or that use inputs whose production involves GHG emissions);

consumers of the goods and services produced by such firms, and consumers whose activities directly produce emissions (driving motor vehicles, heating homes);

those who supply labour and other inputs for which tolal demand by consumers and businesses is likely to decrease as part of reducing overall emissions; and the general public whose taxes are affected by different policies to reduce GHGs. (General tax rates might have be increased if governments attempted to achieve an emissions target by encouraging emissions reductions through subsidy programs or tax incentives: general tax rales might be lowered if revenues were obtained through auctioning of permits.) $)^{\text {"1 }}$
}

How these burdens will be allocated among members of our society and how the incidence issues will be resolved will depend largely upon the design features of the trading system Achieve Domestic Greenhouse Gas Objectives: Options Report, (Ottawa: Tradeable Permits Working Group of the National Climate Change Process, 2000), online: NCCP <www.ncep.ca/html/tables/pdU options/TPWG_en_bw.pd P [TWPG Options Report]. 
adopted by our governments after their political consideration of the equity issues relating to how the burdens should be shared.

Of some relevance in this regard is a communique issued by the Canadian Ministers of the Environment and Energy as part of the NCCP, which indicated that one of their guiding principles would be that "no region of the country should be asked to bear an unreasonable burden and any workable plan must respect that condition."

As part of its analysis and study, the NRTEE commissioned a number of technical papers dealing with a variety of domestic GHG emissions trading issues, one of which was the Design Features Report prepared in 1999. ${ }^{3}$ The Design Features Report addressed five major design issues, each of which included several sub-issues. ${ }^{74}$ The various issues raised in the TWPG Options Report and the Design Features Report are summarized below.

\section{A. Coverage and Point of Imposition of the Permit Trading System}

The TWPG Options Report identified a number of central design issues relating to the scope of coverage of a trading system as well as the point of imposition; noting, for example, that imposing a permit requirement at any point in the product creation and distribution scheme creates a price signal for all users downstream of that point unless a specific exemption is granted. ${ }^{75}$ Similarly, applying a permit to the sale of fuel upstream of the point of the actual creation of the final emissions, for example, would effectively increase the price of fuel at that upstream point. The price increase would likely be passed along the scheme and impact the price paid by the final emitter for fuel; thus providing it with an incentive to reduce $\mathrm{CO}_{2}$ emissions by reducing fuel consumption or switching to a fuel that produces smaller quantities of $\mathrm{CO}_{2}$ when used. The TPWG Options Report also suggests that although it would be possible to create an alternative ration-coupon system to effectively impose permit requirements on the millions of ultimate business and personal consumers of fuel (through their use of cars and trucks, or heating their facilities and homes), "such a system would be [extremely] complex and costly to administrate."

The TPWG Options Report notes that decisions regarding coverage and point of imposition will also be affected by the methods available to monitor GHG emissions. The most practical method of monitoring emissions will depend upon the source. Some emissions. such as those resulting from the combustion of fossil fuels, can be accurately estimated without actual measurement by determining the amount of the substance used to give rise to the emission. Others can be accurately estimated by measurement of the substances used in the production processes or the products produced. Some emissions, such as methane and

". Climate Change Discussion Paper, supra note 4 at 6.

" Erik Hailes \& Robert Hornung. Analysis of Emissions Trading Program Design Features, (Oltawa NRTEE, 1999), online: NRTEl: < www.nrtec-trnee.ca/Publications/PDF/TDFSIGNE.pdP |Design Feaures Reporl].

14 $\quad$ bid. The five overriding design issues include: Issues Relating to the Scope of the Emissions Trading Program; Issues Relating to the Measurement, Reporting and Verification of Allowances and Credits. Issues Relating to the Costs of Trading for Participants; Issues Relating to Jhe Use of Allowances and Credits; and Issues Relating to Changes to the Emission Trading System.

75 Supra note 68 at 6.

" Ibid. 
$\mathrm{NO}_{2}$ emissions from large stationary facilities, can be accurately determined only through direct monitoring. There are some emissions for which there is no practical method of monitoring. These emissions may be capable of estimation in the aggregate, by reference to the nature of the process that results in the emission, the extent to which the process is being undertaken and experimental data. Examples of these emission sources include methane from livestock and landfills or $\mathrm{NO}_{2}$ from fertilizers. Although estimates of this later category of emission types are included in our national GHG inventory, their inclusion in any type of emissions trading system would be impractical given the difficulties of monitoring and the number of individual sources. ${ }^{77}$

The NRTEE Options Report examined four main design alternatives. Two were designed to impose the permit system upstream and two were targeted approaches designed to impose the permit system upon a defined group of large emitters. ${ }^{78}$ The TWPG Options Report, by contrast, examined two primary alternatives with respect to the point of imposition of a permit trading system. ${ }^{79}$ They first considered imposing this system only on large emitters whose emissions would comprise about 35 percent of total greenhouse emissions in Canada. Those who remain outside the system would be regulated through other policy instruments. The second alternative considered was intended to achieve the maximum potential coverage of each type of GHG source. The broad coverage would transmit the GHG emission price signal throughout most of the economy and would allow for a high degree of diversity of choice in the areas and methods of emissions reduction by those affected. Broad practical coverage would cover about 75 percent of total emissions in Canada. ${ }^{80}$

Each of the governments of Canada and Alberta have now declared their intentions to implement domestic emissions trading schemes as a significant component of their overall plans to reduce GHG emissions. Both the federal and the provincial plans propose to make the trading system available to large emitters to provide them with flexibility in complying with emissions reductions, which will be imbedded within negotiated reduction covenants with appropriate regulatory or financial backstops."

\section{B. Scope of the Emissions Trading Program ${ }^{82}$}

\section{GEOGRAPHIC SCOPE}

Economic gains from emissions trading can only result where there are differences in the marginal cost of emissions abatement among the participants in the program. Participants with lower marginal cost structures can obtain a benefit by selling unutilized allowances or credits at a profit. Those with higher marginal cost structures will benefit from the purchase

For a further discussion of monitoring methods, see ibid. at 6 .

Supra note 41 at 47-49.

TWPG Options Report, supra note 68 at 8.

Ibid.

See Climate Change Plan 2002, supra nole 14 at 29-31; Alberta's Climate Change Action Plan, supra note 34 at 15.18 .

The issues relating to geographic scope, scope of included pollutants, sources and sinks, and the scope of the trading market that are summarized in this section are set out more fully in the Design Features Repori, supra note 73 at $\mathbf{3 - 6}$. 
of unused allowances or credits from other participants at a market cost that is less than what would otherwise have been expended in order to obtain an equivalent amount of emission reductions to those covered by the allowances and credits.

Typically, the greater the geographical scope of the trading program, the larger the trading market. The larger the trading market, the greater the diversity of the marginal cost structures of the participants. Accordingly, it is desirable to have as broad a geographical scope as possible. In this respect, it would be preferable to establish a global trading system as is currently contemplated within the Kyoto Protocol. As earlier noted, the Kyoto Protocol contemplates the creation of an international trading system through the Kyoto Flexibility Mechanisms. ${ }^{83}$ Unfortunately, the extent to which these mechanisms can be utilized continues to be the subject of ongoing negotiation and their ultimate scope is unclear.

At the domestic level, the geographical scope of a domestic emissions trading system will be governed by jurisdictional considerations between the federal and provincial governments and the extent to which federal-provincial cooperation can be achieved in order to create a single national market. In addition, any domestic program or programs should contemplate access to Kyoto Mechanisms, should the Kyoso Protocol come into force. The federal and Alberta governments are currently proposing emissions trading systems for large emitters. ${ }^{84}$ Alberta's proposal endorses the concept of allowing participation in national, continental and international trading systems that may allow for larger emissions reduction opportunities to be pursued, ${ }^{85}$ while the federal plan endorses the idea of allowing access to international permits to provide flexibility. ${ }^{86}$

There are also environmental considerations that may impact the desired geographical scope of a domestic emissions trading program. Greenhouse gases have no local environmental impacts; the effect of a given discharge of GHGs is identical regardless of where the emission occurs. This consideration should facilitate global trading of GHG emissions.

There is, however, usually an ancillary benefit to reductions in GHG emissions with respect to other pollutants which do have more localized adverse environmental or health effects. ${ }^{87}$ As a result, it may be desirable to promote actual GHG emission reductions in a particular locale or jurisdiction, rather than encourage the implementation of those reductions outside of the local jurisdiction as may result through emissions trading. Trading can give rise to local health and environmental concerns due to increased or continued emissions of ancillary pollutants.

nt See Climate Change Plan 2002, supra note 14 at 29-31: Alberta's Climate Change Action Plan, supra note 34 at 15-18. 


\section{SCOPE OF INCLUDED POLLUTANTS, SOURCES AND SINKS}

In addition to geographic scope, it is necessary to consider the scope of the pollutants, sources and sinks that will be included in the emissions trading system. Like geographical scope, it is more economically efficient to include as many gases, sources and sinks as are possible within the system, as that would lead to a greater diversity in marginal costs of emissions reductions among various gases, sources, sinks and reservoirs. The inclusion of sinks in emissions reductions calculations was recognized in art. 3 of the Kyoto Protocol. The Government of Alberta has undertaken the potential design of a domestic trading system and has included trading of GHGs as well as of air contaminants such as $\mathrm{SO}_{2}$ and $\mathrm{NO}_{2}{ }^{88}$

The Kyoto Protocol, however, left a number of issues to be resolved through subsequent negotiations; the scope of any domestic emissions trading program will be affected by the outcome of these negotiations. Progress has recently been made with respect to determining the scope and meaning of the sinks referenced in art. 3 of the Kyoto Protocol. Negotiations during COP-6 and COP-7 resulted in an agreement to include "human-induced activities" such as crop land management and forest management as part of the calculations. There were, however, caps set on "the amount of reduction credit that could be claimed through forest management." ${ }^{\text {89 }}$

\section{SCOPE OF TRADING MARKET}

The success of an emissions trading program can be expected to depend, in large measure, upon the extent to which the participants are able to form an efficient and competitive market for trading. This requires a sufficient number of participants and sources to prevent any one participant or source or small group of participants or sources from influencing the market. The small number of market participants in the Canadian ozone depletion trading program, undertaken in conjunction with the Montreal Protocol, inhibited inter-participant trading because of competitive concerns and prompted the regulators to distribute methyl bromide allowances to end users rather than to the limited number of importers in that program. ${ }^{90}$

It is likely that a voluntary credit or allowance trading program would have a smaller number of participants than a program that was nationally mandated. Because the program is voluntary, however, market power is less of a concern. With respect to mandatory programs, there should be a national commitment resulting through federal-provincial cooperation in order to include enough sources to create a competitive market.

If separate federal, provincial and territorial programs are implemented, smaller jurisdictions will not likely have access to a sufficient number of sources to create a competitive market or the markets will be dominated by a few large sources. Although some of these issues could perhaps be addressed within other design considerations, such as the

kx Alberta's Climate Change Action Plan, supra note 34 at 19.

"Matthew Vespa, "Climate Change 200I: Kyoto at Bonn and Marrakech" (2002) 29 Ecology L.Q. 395 at $409-11$.

'*1 Supra note 44 
mode of the distribution of allowances (whether gratis or by auction or otherwise), it would seem preferable from an economic standpoint to implement a national program in which competitive concerns would be greatly alleviated. Further, linkage with the intemational trading market would eliminate the market power concern completely. While both the federal and Alberta proposals seem to contemplate a voluntary system and one or more linkages with other domestic, continental or international systems, the extent to which the governments will be prepared to coordinate their efforts into either a national trading system or a number of parallel domestic systems with appropriate linkages remains unclear and is the subject of continued negotiation within the NCCP. ${ }^{91}$

Different types of GHGs and sources are better suited to different trading program designs and different source categories are better regulated by federal, provincial or territorial governments. As a result, a national effort to meet Canada's emission reduction commitments might include multiple emissions trading programs. Although it is possible to still create a single market for GHG allowances and credits originating from multiple trading programs, a number of additional design issues arise that must be addressed.

In theory, the individual programs can be integrated into a single, trading market provided that the regulators of each program enable its participants to use allowances or credits created in any other domestic program or any valid assigned amount issued pursuant to the Kyoto Protocol or arising pursuant to the Kyoto Flexibility Mechanisms in order to achieve compliance with the participants' emissions allowance. If all regulatory authorities for all relevant trading programs agree, then the market value of all allowances should be identical regardless of their source, and all participants and all programs, whether mandatory or voluntary, would face the same marginal cost of control.

While the value of allowances issued by each regulatory authority will remain constant regardless of their source, the same cannot be said with respect to credits created within different systems unless the credits are certified by the regulatory authority before they are sold, whether by way of audit or otherwise. If, however, credit trading operates with buyer liability, then there is risk of rejection when the buyer attempts to use them for compliance purposes. This would likely result in the value of the credits being discounted accordingly in the marketplace. It is suggested in the Design Features Report that the risk of regulatory rejection could be addressed by either the purchase of insurance by the buyer or by simply allowing the market prices of credits to reflect the risk of rejection. 


\section{MEasurement, Reporting and Verification Of AllowanCes ANd CREDIts ${ }^{92}$}

\section{MEASUREMENT}

Credit trading programs require monitoring systems to measure or calculate actual emissions and to estimate avoided emissions. Allowance trading programs also require a monitoring system to measure or calculate actual emissions to ensure compliance. The integrity of the emissions trading system will depend upon the quality of the emissions or substance monitoring systems used. .3 $^{3}$

Because monitoring systems can be costly to install and operate, the regulatory authority may be prepared to accept alternative methods of emission measurement. As discussed in more detail in subsection $\mathrm{B}$ above, emissions monitoring systems will differ by gas and source category. Some GHG emissions, such as energy related $\mathrm{CO}_{2}$ emissions, can be estimated quite accurately from other information, such as energy use by fuel type and emissions factor by fuel type.

Consideration will also have to be given to protocols to be followed in the event of failure of a monitoring system. Because the parties to the Kyoto Protocol report their emissions by reference to an inventory methodology developed by the IPCC, rather than summing actual emissions reports by individual sources for each party, there is no direct correspondence between the monitoring systems that need to be used within the domestic trading system and the national emissions inventory.

\section{REPORTING}

Participants in allowance or credit trading programs must report their actual emissions, the emissions reduced or sequestered and the credits created to the regulatory authority. In addition, it will be necessary for parties to a credit or an allowance trade, to notify the central registry of the transaction in order that it can be reviewed, verified and confirmed. Accordingly, those designing the emissions trading systems will need to decide upon the requirements for a suitable reporting system including the information that is to be reported, the format in which it is to be gathered and prepared and the frequency with which it must be reported. In Alberta, large emitters (whose annual $\mathrm{CO}_{2} e$ emissions exceed 100 to 150,000 kilotonnes) will be required to report their annual GHG emissions with the first reporting to occur in 2004 for emissions in 2003. ${ }^{94}$ The Government of Alberta has indicated its commitment to allow for the creation of an effective national system of GHG reporting while avoiding duplication of reporting requirements between federal and provincial authorities. ${ }^{95}$ set out more fully in the Design Features Report, supra note 73 at 7-9. 


\section{VERIFICATION}

Central to the trading of emissions allowances is the question of which party is responsible for ensuring that the allowances are valid and transferable. If the seller is responsible, the buyer can accept the allowances knowing that they will be valid, and if the seller does not meet its commitments, it will incur penalties for non-compliance. If the buyer is responsible, and the seller later needs the transferred allowances to achieve compliance, the sale may be invalidated, the seller might keep the allowances and the buyer could be required to resort to its contractual remedies against the seller to recover any payments made. In addition, the buyer may suffer further losses as a result of the need to purchase replacement allowances in order to achieve its own compliance.

While both seller and buyer liability options are available in the design of a credit trading system, each has its own advantages and disadvantages. Seller liability effectively imposes upon the regulatory authority issuing the credit the obligation to certify them before they can be sold. While the buyer can then be confident that the credits it has purchased will be accepted by the regulator when used for compliance purposes, seller liability increases the time and cost involved in creating and selling the credits to the seller and the regulator. On the other hand, buyer liability shifts the burden of validation of the credits from the regulatory authority to the buyer. Because buyers may be more reluctant to purchase credits due to the risk of rejection in a buyer liability scenario, trading activity may be lower and prices would tend to be lower then a seller liability system.

\section{AUDIT AND VERIFICATION $\%$}

In an allowance trading program, regulatory authorities will need to verify for each participant that the actual emissions reported are complete and accurate, that the allowances used for compliance are valid, that the emissions monitoring system has been tested and complies with the established criteria, that missing data protocols have been implemented properly by the participant and that actual emissions have been reported in accordance with the requirements.

In a credit trading program, the regulatory authority must ensure that the credit creation action meets the established criteria. Such criteria will probably include requirements that the credits are real, measurable, long-term and additional to what would have occurred otherwise. Whether audit and verification of credit occurs shortly after they are created or as part of the compliance process for buyers will depend upon whether a system of buyer liability or seller liability is utilized. As noted in the Design Features Report, generally "[a]udit and verification by the regulatory authority is not necessary in a voluntary program, although participants could choose to have an independent entity perform this function."

W. The issues relating 10 audit and verification that are summarized in this section are set out more fully in the Design Features Report, supra note 73 at 10. 


\section{E. MARKET INSTITUTIONs ${ }^{93}$}

The creation of an emissions trading program necessarily implies the creation of a market within which the participants can trade their allowances and credits and which will require some degree of infrastructure to facilitate trading and the regulation of the marketplace. While the volume of emissions trading has not historically been sufficient to warrant the involvement of a centralized trading institution, such as a commodity exchange, there has been sufficient activity to attract the attention of brokers. Thus far, the activity of brokers in emissions trading markets are analogous to the services provided by real estate brokers, though they may offer ancillary services as well.

Because participants in the markets are typically large and sophisticated firms capable of protecting their own interests, no emissions trading program has attempted to regulate brokers nor to establish an infrastructure that might enhance the integrity of the market in a similar fashion to a stock or commodity exchange.

Given the anticipated volumes of trades that would likely occur with the creation of allowance trading programs for GHGs in Canada, one might anticipate that more formal market institutions may evolve. The Government of Alberta has observed that the province is well positioned to build on its experience in developing energy markets and defining commodities that can be traded on the open market. ${ }^{90}$

\section{F. OPERATION OF A REGISTRY ${ }^{100}$}

The creation of a registry is essential to any emissions trading program. The registry tracks the allowances or credits acquired, disposed of or retired by each participant, as well as their overall balance. Each participant's account will be reduced by the amount of allowances or credits utilized or sold and will be increased by the amount of any allowances allocated or purchased. In credit trading programs, the registry also usually maintains a record of how credits were created as well as information used to assist with clarification.

If the Kyoto Protocol comes into force, federal and provincial authorities will need to establish a single global registry or multiple national registries in order to track holdings of assigned amounts, JI reductions, CDM credits and IETs. Regardless of whether a global registry is established, it may well be advisable for Canada to establish a national registry for the domestic program or programs that could in turn transfer data to the global registry.

In Alberta's Climate Change Action Plan, the Province of Alberta has indicated that it will work with Climate Change $\mathrm{Central}^{101}$ and existing registries such as Voluntary Challenge and

The issues relating to market institutions that are summarized in this section are set out more fully in the Design Fearures Report, ibid. at 10-11.

7) Alberta's Climate Change Action Plan, supra note 34 at 18.

Itw The issues relating to the operation of a registry that are summarized in this section are set out more fully in the Design Features Report, supra note 73 at 12.

(14) Climate Change Central is a public-private partnership that promotes the development of innovative responses to global climate change and its impacts. Climate Change Central builds links and relationships between businesses, governments and other stakeholders in Alberta interested in pursuing 
Registry (VCR Inc.) ${ }^{102}$ to establish an effective emission reduction registry. Existing registries will be considered for this role, with the goal of ensuring that registered emissions reductions have a clear and unique title and can form the basis for transparent verification protocols. ${ }^{103}$

\section{G. Trading Costs of Participants ${ }^{104}$}

\section{Price Disclosure}

Freely available information on prices of recent trading transactions helps to facilitate other transactions and allows firms to evaluate alternative compliance strategies. The buyer and seller in a particular transaction, however, may consider the price at which they have traded allowances to be proprietary. Price disclosure is more important if the volume of trading activity is low because potential buyers and sellers will be less likely to know someone with recent reliable information that they are prepared to share and available information is likely to be inconsistent.

Where trading volumes increase to the point where brokers are involved, brokers will publish pricing information in a manner that maintains the confidentiality of the individual buyers and sellers.

Though no emissions trading program has yet required public disclosure of the price for a given transaction, some require that price information be reported to the regulatory authority so that it may be compiled and released without compromising issues of confidentiality.

In an allowance trading program where allowances will be distributed by auction, price disclosure for the auction will be automatic. In a credit trading program, the volumes of trades are traditionally less than an allowance trading program. In addition, the value of credits will be more dependent upon the attributes of each credit offered in each transaction. As a result, participants should be required to provide their pricing data to the regulatory authority, who would be able to make the data publicly available without compromising the confidentiality of the participants.

\section{TRANSACTION COSTS}

An emissions trading program should be designed to minimize transaction costs by reducing approval and review requirements, processing times, uncertainty and participation by small sources. While audit and verification processes and enforcement of penalties for non-compliance are clearly essential, other review or approval requirements should be is to provide the means for promoting, assessing and recognizing the effectiveness of the voluntary approach in addressing climate change. Its website is located online: <www.vcr-mvr.ca/index_e.cfm>. Alberta's Climate Change Action Plan, supra note 34 at 18. 
eliminated unless the expected benefits of the requirements will clearly exceed any anticipated increase in transaction costs.

Lengthy processing times for approvals and compliance verification also lengthen the time period during which neither the buyer nor seller can utilize the allowances, credits or money tied up during processing and accordingly increases opportunity costs for the parties.

While some risks are inherent in any trading system, many will be within the control of the participants to manage as they see fit. Participants have some measure of control over their own emissions, the quality of credits they purchase, the reliability of parties they trade with and their price risk (by undertaking hedging strategies). The Government of Canada explicitly recognizes price risk in its climate change plan. Although it indicated that industry must assume its normal responsibility for managing risks associated with price fluctuations, it indicated a willingness to work with industry on options to provide a manner of protection in the event that carbon price remains high for extended periods of time. ${ }^{105}$

Uncertainties that result from frequent program changes, inconsistent regulatory decisions and similar factors, however, should be minimized.

While a consideration of the anticipated transaction costs associated within a particular trading program altemative is relevant in the final analysis, the Design Features Report suggests that the transaction costs are likely to be a relatively small part of the overall cost of limiting the emissions. ${ }^{106}$

\section{FEES}

While voluntary emissions trading programs are typically financed by the participants, an emissions trading program implemented by a regulatory authority will necessarily require some source of funding in order to finance its administrative obligations. While some programs have levied fees on participants or transactions to help cover administrative costs, or both, it is arguable that the authority should be responsible for its own costs, as the imposition of additional fees will inhibit transactional activity. As with any other governmental or quasi-governmental service, however, the imposition of fees or levies will likely be more palatable to the participants to the extent that they help the authority to administer the trading program more efficiently and without delays and lower consequent ancillary transaction costs. 


\section{H. USAGe Of Allowances and CRedits ${ }^{107}$}

\section{BANKING}

Some emission trading systems allow the banking of allowances or permits so they can be utilized in a period after that in which they were created. Banking provides additional flexibility to the source to adjust for fluctuations in economic, weather, operating or other conditions. They have also proven to be useful in helping the participants to adjust to more stringent emissions limitation commitments. ${ }^{103}$ The U.S. Heavy Duty Vehicle Emissions Standards system, however, reduced somewhat the benefits that would accrue from banking, as the banked allowances were discounted somewhat to encourage an early response to the new standards.

As with considerations respecting the geographical scope of the emission trading system, the use of banking of GHG emissions may impact the local health or environmental effects of other pollutants such as $\mathrm{SO}_{2}, \mathrm{NO}_{2}$, VOCs and particulate matter (PM) in the near term while permits were banked and held for use in future periods. Banking of GHGs could result in increased emissions of these ancillary sources in the future.

As a result, the introduction of the concept of banking into a domistic GHG emissions trading program would be desirable in order to give the participants greater flexibility to achieve compliance with no direct environmental risk. It will, however, be necessary to ensure that the regulatory authorities ensure that either the banking system address or the regulations effecting the ancillary pollutants prohibit increases of their emissions to unacceptable levels due to the use of banked GHG allowances or credits.

\section{AllowaNCE OR CREDIT LIFE}

If the domestic emission trading system permits banking of credits and allowances, consideration must be given to the effective life of the allowances or credits issued. While some emissions trading programs allow for an indefinite life of the credits or allowance, others will limit the life of those credits and allowances in order to achieve specific emission reduction targets. The Government of Canada has hinted that it may consider options in order to enable industry to respond to exceptional circumstances if the nine year time period from now to the end of the first Commitment Period under the Kyoto Protocol is too short to allow for needed technological development and strategic capital turnover. ${ }^{103}$

The issues relating to banking, allowance or credit life, borrowing, compliance and penaltics for noncompliance that are summarized in this section are set out more litly in the Design fectures Report. ibid. at $15-20$.

For example, the U.S. Heavy Duty Emissions Standards process cnabled manufacturers to resort to banking in order to meet standards set to come into force in 2003 (U.S. Environment Protection Agency, "Control of Air Poltution from New Motor Vehicles and New Motor Vehicle Iingines. Proposed Non-Conformance Penalties for 2004 and Later Model Year Limissions Standards for HeavyDuty Diesel Engines and Heavy-Duty Vehicles," online: Federal Register linvironmental Documents <wuw.epa.gov/fedrgstr/EPA-AIR/2002/January/Day-16/al 109.hım>). See also Pant IV $\Lambda$ above. 


\section{BORROWING}

It is possible for an emissions trading system to allow a participant who is unable to achieve compliance within a particular period to borrow future allocations of allowances or credits. Borrowing would be a substitute for purchasing surplus credits or allowances from another participant in the market.

Because credits are not usually issued until the actual reduction or sequestration action has been implemented so that the quantity of emissions avoided or sequestered can be documented and certified, borrowing is not particularly well-suited to a credit trading program.

In a domestic system of allowance trading, borrowing weakens the regulatory enforcement environment and creates "credit" risk for the regulatory authority. Allowances, which have been borrowed and applied to excess emissions for use in earlier periods, are lost in the event that the borrowing entity ceases operations or becomes insolvent. In essence, the excess emissions from the earlier period will never be offset in a later period.

In addition, borrowing competes with the allowance sale market assuming that the cost of borrowing is less than the cost of the allowances at market price.

If banking is to be contemplated within the context of the Kyoto Protocol then, at a minimum, the system would need to ensure that no borrowing can occur beyond the end of the Compliance Period in 2012.

\section{Tiu: COMPLIANCE PERIOD}

The compliance period is the interval within which participants must establish that their actual emissions for the period are less then their allowance holdings in the case of an allowance trading program or less than the emissions allowed by applicable regulations and net credit holdings in the case of a credit trading program.

Unlike domestic trading programs that usually have one year compliance periods, the Kyoto Protocol provides for a multi-year compliance period being 2008 to 2012. The multiyear compliance period was established in recognition that GHGs have extremely long atmospheric lives and that variations in emissions over just a few years has a negligible effect. On the other hand, there are a number of variables beyond the control of the emitter that may negatively impact its ability to reduce emissions during a given period in the near term such as weather and economic conditions.

The Design Features Report suggests that the arguments for a one-year compliance period include the following:

(a) it is a standard for other emissions trading programs and is consistent with many other corporate reporting requirements, such as financial reporting and tax calculations; 
(b) it helps to strike a balance between the reduced administrative cost of establishing compliance achieved by less frequent compliance confirmation, and the increased risk of ultimate non-compliance by sources that become insolvent, cease to operate or are simply in a position of non-compliance at the end of the program in the absence of more frequent compliance reviews; and

(c) it would be consistent with the annual reporting obligations of Canada under the Kyoto Protocol. ${ }^{10}$

\section{Penalties for NON-COMPLIANCE}

Under a credit creating program, participants are subject to mandatory performance standards such that sources that reduce their emissions below the system's cap will earn credits for the difference. Sources whose emissions are above the regulated level can purchase credits for the difference. Because sources will be required to report the manner in which they achieve compliance, those who are found not to be in compliance could be subject to compliance penalties including fines, loss of credits or perhaps criminal sanctions.

The climate change plans of each of the governments of Canada and Alberta contemplate a system of mandatory performance standards and penalties for non-compliance. "'Each plan envisages the negotiation of sectoral agreements with specific economic sectors, which will establish measurable emission reduction goals based on emissions per unit of production or emissions intensity. The creation of emission intensive rather than absolute emissions reduction targets is intended to avoid the displacement of investment, jobs and emissions to nations without GHG emissions targets. It would also take into account an emitter's changes in production, as permits received would shrink or grow as did production. It is also contemplated that the sectoral agreements could be used to address competitiveness concerns, expected technological or other opportunities or any other initiatives to reduce emissions.

While Alberta's Climate Change Plan contemplates the negotiation of sectoral agreements with sector associations "in order to bring companies to the table,"112 it does not specify exactly how the individual companies will be legally bound by the negotiated targets. It does, however, indicate that companies who choose not to sign onto a sectoral agreement will be subject to at least the same reduction requirements.

Under a mandatory allowance scheme that is designed to achieve a national commitment, non-compliance by each participant has an effect on compliance with the national commitments. Accordingly, it is necessary to penalize those participants who are not complying with their allocated obligations. These penalties would normally take the form of an automatic loss of allowances from future gratis allocations equal to the excess emissions, plus fines and possible criminal penalties in exceptional circumstances. If allowances are

111 See Climate Change Plan 2002, supra note 14 at 31; Alberla's Climate Change Action Plan, supra note 34 at 15-17. 
distributed by auction, penalties and fines will be the only compliance options available. One could, however, characterize the penalties in terms of the amount that must be expended to purchase sufficient allowances to offset the excess emissions plus a further incremental fine as further penal sanction.

Although each of the federal and Alberta climate change plans appear to contemplate that the sectoral agreements would be "backstopped" by legislative, financial and regulatory provisions and penalties; the plans are short on details of the mechanics of these consequences for non-participation or non-compliance. It is also unclear how the use of emission reduction targets based on emission intensity will dovetail with Canada's absolute emission reduction targets assumed under the Kyoto Protocol. ${ }^{113}$

\section{Method of Allocation Of Allowances ANd Permits ${ }^{1 / 4}$}

The TPWG Options Report focused on how the initial allocation of permits would impact issues of jurisdictional, sectoral and corporate inequalities created by the imposition of a tradable permit scheme. The method of initial allocation of permits will have significant implications for Canadians. Upon the Kyoto Protocol coming into force, Canada's 565 mega tonnes of $\mathrm{CO}_{2} \mathrm{e}$ emissions for the commitment period will be distributed to Canadians in a manner consistent with a set of GHG policies that the Government of Canada develops in order to transfer ownership rights in the permits to eligible participants to enable them to buy and sell the permits.

The TWPG Options Report emphasizes that "[t]he approach for permit allocation will affect the distribution across sectors, regions and income groups of the burden of achieving the overall emissions reduction targeted by the permit system. I may also influence the pattern of actual emissions reductions."1's

\section{Distribution BY AUCTION}

The TWPG Options Report notes that a domestic tradeable permits system with distribution by auction to the highest bidder raises the price of emission-intensive activities and is intended to induce change that will lower emissions. This is achieved by the following process, as outlined in the TWPG Options Report:

"I' Notwithstanding the indications in Alberla's Climate Change Plan that emission reduction targets would be based on emission intensity and that participation in any emissions trading program would be voluntary, Alberta Environment has now received a Preliminary Analysis and Discussion Document prepared in connection with a major study being undertaken to examine the feasibility of implementing a made in Alberta emission project. The document addresses a range of design options including the use of allowances and permits, voluntary and mandatory participation and various allocation schemes for permits and allowances. Accordingly, this article will address a varicty of issues relating to the allocation of allowances and permits notwithstanding the contents of either the Climate Change Plan for Canada or Alberta's Climate Change Plan.

111 The issues relating to the method of allocation of allowances and permits that are summarized in this section are set out more fully in the TIWPG Options Report, supra note 68 at 9.12. 
The requirement to submit permits, which are acquired in the market either at government auctions or in the secondary market, raises the cost of emission-intensive activities. Consumers face higher prices for fossil fuels and for goods whose production is emission-intensive, as firms pass on the costs of their permit requirements.

The auction revenue received by the government is used to reduce taxes.

Households thus face higher prices driven by auctioned permits, and (at least partially) offsetting tax reductions, financed by the auction revenuc. ${ }^{116}$

There are, of course, circumstances where firms will be unable to pass price increases on to their consumers in order to provide such firms with sufficient revenue to cover the costs of their emission reduction strategies or even the costs of permits. Such firms will be required to share the burden of achieving GHG reductions with consumers. The TWPG Options Report suggests there are two types of situations where firms will not be able to pass on the higher costs associated with emissions reduction activities to consumers:

[W] here industries compete in international markets dominated by non-Annex $B$ producers, who face no constraint on emissions under the Kyoro Protocol, intermational and Canadian prices would be unaffected by the pricing of domestic emissions in Annex B countries; [and]

[w] here existing capital is significantly more emissions-intensive than competitive alternative technologies, prices will rise less than the permit costs associated with continuing to operate such existing capital. Owners of the capital would suffer capital losses. ${ }^{117}$

\section{GRATIS AlLocation OF PERMits}

The above noted consequences, international competitiveness and capital losses, suggest that there are two important motivations for a gratis allocation of permits (although it is important to note, however, that there are other approaches that could achieve the same result.)

The gratis allocation approach to the competitiveness issue contemplated in the TWPG Options Report involves an "ongoing allocation to firms in eligible industries on the basis of benchmark emissions intensity rates multiplied by the firms' current levels of the specified types of output."118 Firms would be incented to reduce their emissions in order to achieve the benchmark emission intensity rates but would face no cost disadvantage relative to nonAnnex $B$ producers if they adopted or surpassed the technology and practices upon which the benchmark was based. Implementation of such an approach would not be without significant challenges. Negotiations would be complex and, to a certain extent, could be perceived as arbitrary.

The TWPG Options Report suggests that gratis permit allocations intended to compensate for capital loss would be expected to be both "partial, in that the allocation of permits would be equal to only a fraction of expected emissions level; and temporary, given that a firm's 
capital business assets, whose value would be adversely affected by the imposition of a permit requirement, would not have been expected to last indefinitely."119 Compensation for capital losses could be partially addressed through a distribution of a portion of the auction revenue to those affected.

The TWPG also examined the role in which grandfathering could be used in the context of gratis allocation of permits to emitters based on their historical emissions. Grandfathering is generally seen as recognizing past investments, easing the adjustments faced by industry and reducing business uncertainties. Grandfathering, however, is also recognized as having several drawbacks.

Where a recipient of gratis permits on a grandfathered basis is in a position to make very inexpensive major reduction in emissions, the value of the permits it receives may far exceed any net cost it has to incur. Permit amounts provided for in historical grandfathering may diverge sharply from the patterns of expected capital losses, as different emitters will have different technological opportunities to reduce emissions. Firms' capital assets will vary in the remaining useful lives and the ability of firms to increase prices for emissions-intensive products will vary, providing different degrees of offset on the revenue side to the cost increase resulting from the requirement to acquire permits to match emissions.

The grandfathering approach also has serious limitations as a method of addressing international competitive issues. As it may cover sectors that do not face significant competition from non-Annex B producers and because the allocations are not tied to continuing production, grandfathering does not address growth and new entrance nor does it address contractions in the face of reduced productions and shutdown.

As a result, the TWPG contemplated a framework for allocation that is composed of:

auctioning of the total supply of permits less the allocations under the following two gratis components, with revenue recycled in a manner to address equity and efficiency objectives not addressed by the two gratis components (for example, through reductions of personal and corporate income taxes);

a continuing gratis allocation of permits to address competitiveness of industries competing primarily with producers in non-Annex $B$ couniries; and

a transitional gratis allocation to firms in sectors that would be expected to suffer significant capital losses because of the reduction in value of their existing capital stock that results from the imposition of a TEP system with relatively short notice. 120

\section{Canadian Legislative Authority for IMPLEMENTING EMISSIONS TRADING INITIATIVES}

Given the foregoing, it is likely that federal and provincial cooperation will be a key component of the design and implementation of a national domestic emissions trading system for GHGs. Unless otherwise noted, the following discussion with respect to division of 
powers and the establishment of an emissions trading system in Canada is a synthesis of another NRTEE position paper, "Legal Authority for Emissions Trading in Canada."121

The Constitution Act, $1867^{122}$ sets out the rules by which Canada is governed but it does not expressly mention the environment and its management. Therefore, the regulation of environmental matters cannot be specifically determined to fall within the exclusive realm of either the federal or provincial governments. ${ }^{123}$ The courts have also outlined the approach that is to be taken when the constitutional validity of a legislative enactment relating to the environment is at issue.

The court then is to examine:

the legislative powers listed in the Constimution to see if the provision falls within one or more of the powers assigned to Parliament or to the provincial legislature that enacted the legislation. If the provision falls within the parameters of any such power, then it is constitutionally valid. The validity of a legislative provision, including one related to environmental protection, must be tested against the specific characteristics of the head of power under the Constitution that purportedly justifies it. ${ }^{124}$

While the courts have recognized that the Constitution should be interpreted in a manner that would afford both levels of government "ample authority to protec: the environment, the general structure of the Constitution must be respected, including maintaining the balance of Canadian federalism." 125

\section{A. FEDERAL AUTHORITY}

At the federal level, there are three primary heads of power that could be said to support emissions trading legislation:

1. the peace, order and good government power; ${ }^{26}$

2. the criminal law power; ${ }^{127}$ and

3. the trade and commerce power. ${ }^{128}$

"The power to make laws for the 'Peace, Order and Good Government of Canada' ('POGG') is residual in nature in its relationship to the provincial heads of power."129

Joseph F. Castrilli. "Legal Authority for Emissions Trading in Canada" (Toronto: Pilot Emission Reduction Trading (PERT), 1998), Appendix 1 to Elizabeth Atkinson. The legislative Authority (o Implement a Domestic Emissions Trading System (Ottawa: NRTEE. 1999), online: NRTEE <www nrtee-trnee.ca/Publicalions/PDF/TLGAUTHE.pdßs. 
Accordingly, this head of power may only be used "to support federal legislation if the subject matter of the legislation is confined to 'matters not coming within the classes of subjects' assigned by the Constitution to provincial legislatures."130

The Supreme Court of Canada has developed a branch of POGG known as the National Concern Doctrine, which has been used to uphold federal environmental legislation. ${ }^{13 t}$ As set out in the Legal Authority Report, the National Concern Doctrine has the following characteristics:

1. The national concern doctrine applies to both new matters which did not exist at Confederation and to matters which, although originally matters of a local or private nature in the province, have since, in the absence of national emergency, become a matter of national concern;

2. For a matter to qualify as a malter of national concern it must have a singleness, distinctiveness and indivisibility that clearly distinguishes it from matters of provincial concern and a scale of impact on provincial jurisdiction that is reconcilable with the fundamental distribution of legislalive power under the Constitution;

3. In determining whether a matter has attained the required degree of singleness, distinctiveness and indivisibility that clearly distinguishes it from matters of provincial concern, it is relevant to consider what would be the effect on extra-provincial interests of a failure to deal effectively with the control or regulation of the intra-provincial aspects of the matter. ${ }^{132}$

Once a matter has been characterized as a matter of national concern, "Parliament has an exclusive jurisdiction ... to legislate in relation to the matter, including its intra-provincial aspects." 133 The courts have noted that matters of environmental concern are all pervasive and, if the environment was accepted as falling within the legislative domain of Parliament under the National Concern Doctrine, the division of legislative power in Canada could be radically altered. ${ }^{134}$ Insofar as the court in other cases, interpreting federal environmental legislation, has indicated that the Constitution should be broadly interpreted to afford both levels of government sufficient means to protect the environment while maintaining the general structure of the constitution, ${ }^{135}$ it has been observed that the courts would be unlikely to enthusiastically adopt the National Concern Doctrine as a basis for upholding federal legislation, thereby removing the area from the possibility of concurrent provincial legislation. ${ }^{136}$

It has been suggested that the power conferred on Parliament to make criminal law might be relied upon to enable Parliament to assume jurisdiction with respect to emissions trading

Ibid., citing Peter W. Hogg, Constitutional Law of Canada, 4th ed. (Scarborough: Carswell, 1997) at 443-44, 446.

III Ibid., citing R. v. Crown Zellerbach LId., [1988] I S.C.R. 401 at 432 [Crown Zellerbach].

11: Jbid. at 10-11, citing Hydro-Quebec, supra note 123.

III Crown Zellerbach, supra note 131 at 432 , cited in Castrelli, supra note 121 at 11.

in Castrilli, ibid., citing Hydro-Québec, supra note 123 at 288.

ins Ibid, citing Friends of the Old Man River Society v. Canada (Minister of Transport and Minister of Fisheries and Oceans), [1992] I S.C.R. 3 at 62-65 
regimes. In order for a federal law to be valid under the criminal law power, however, "the statute must meet two requirements. First, it must have a valid criminal law object or purpose. Second, it must address the object by means of prohibition backed by penal sanctions." Hydro-Québec, the Court declared that control of toxic substances is a public purpose sufficient to support a criminal prohibition. ${ }^{138}$

The issue of whether the criminal law power would support the creation of an environmental regulatory regime such as the Canadian Environmental Protection Act ${ }^{139}$ was central to the Hydro-Québec decision. The majority held that Part II of CEPA was a valid exercise of the federal criminal law power in that the regime sought to control toxic substances through a series of prohibitions through which penal sanctions were attached and in a manner sufficiently restrictive to give the provinces ample scope for continued action. There was a strong dissent that held that CEPA was not valid criminal law and was in substance regulatory law. ${ }^{140}$ The outstanding question of whether GHG emissions are toxic substances may be relevant to a future determination of whether an emission trading system targeting GHGs could be said to fall under the criminal law power.

The final head of power on which the federal government may rely is the power conferred on Parliament by the Constitution to make laws in relation to the "the regulation of trade and commerce."141 The trade and commerce power has, however, historically been narrowly interpreted by the Privy Council so as to accommodate provincial power over "property and civil rights." 142 Although the Supreme Court of Canada has, since the abolition of appeal to the Privy Council, expanded the ambit of the trade and commerce power somewhat, the power has not yet been relied upon as a basis for upholding federal environmental legislation. ${ }^{143}$

Because the trade and commerce power has traditionally been interpreted as including regulation of interprovincial and international trade and commerce and general trade and commerce affecting the entire country, emissions trading, by its very nature, may represent a realistic opportunity for the federal govermment to test the scope of the trade and commerce power in relation to environmental law. ${ }^{144}$

\section{B. Provincial Authority}

The key head of power that supports provincial legislative authority over environmental matters is "property and civil rights in the Province." 145 "Property and civil rights has been the basis for upholding the constitutionality of most pieces of provincial environmental legislation."146 Although the provincial power over property and civil rights will be the

Ibid. at 12, citing Constitution, s. 91(27).

Ibid. at 13.

R.S.C. 1985 , c. 16 (4th supp.) [CEPA].

Castrilli, supra note 121 at 13.

Ibid. at 14, citing Constitution, s. 91(2).

Ibid, citing Consituition, s. 92(13).

Ibid.

lbid.

Ibid. at 18, citing Constitution, s. 92(13).

Ibid., citing R. v. Lake Ontario Cement Lid., [1973] 2 O.R. 247 at 254-55. 
primary constitutional basis for provincial emissions trading legislation, the legislation must be directed at only intraprovincial emissions trading as the power can only have incidental effects on other interprovincial interests. ${ }^{147}$

As a result of the foregoing, it would seem that the trade and commerce power would enable the federal government to create a broad and flexible approach to emissions trading while "allow[ing] concurrent and compatible provincial legislation relating to intraprovincial aspects of emissions trading." 148

\section{Federal Legislation Respecting Emissions Trading}

In 1999, the federal government passed the Canadian Environment Protection Act, 1999. ${ }^{149}$ Section 322 provides:

The Minister may establish guidelines, programs and other measures for the development and use economic instruments and market-based approaches to further the purposes of this Act, respecting systems relating to

(a) deposits and refunds; and

(b) tradeable units.

CEPA 99 authorizes the Minister to consult with provincial governments and representatives of industry and labour, among others, to establish these guidelines and programs. ${ }^{150}$ Much is left to be determined by regulation. ${ }^{\text {is1 }}$ Writing prior to CEPA 99 's passage into law, the Legal Authority Report stated that the provisions of CEPA 99 constitute perhaps the most extensive statutory authorization for an emissions trading program in Canada. They contain authority for many components that traditionally have characterized such regimes. ${ }^{132}$

It appears that the federal government was conscious of division of powers when drafting this legislation. The Preamble to CEPA 99 "recognizes that all governments in Canada have authority that enables them to protect the environment and recognizes that all governments face environmental problems that can benefit from cooperative resolution." Further reference is made to "human health," which relates to the federal government's criminal law power.

In relation to establishing guidelines and programs under CEPA 99, on 21 November 2002, the federal government put forward a new Climate Change Plan for Canada, which sets out the government's policy and goals regarding covenants and emissions trading by industry. ${ }^{153}$

Ibid.

lbid. at 19.

S.C. 1999. c. 33 [CEPA 99]. The proposed version of CEPA 99 is discussed in delail in Castrilli, supra note $|2|$ at 23-25.

Jbid., s. 323.

lbid., ss. 325-26.

Supra note 119 at 24.

Climate Change Plan 2002, supra note 14. 
Covenants would offer an alternative to a regulatory approach, whereby companies and sectors could enter into agreements with the government; should they comply with these agreements, the companies and sectors would be exempted from the climate change levy. ${ }^{154}$ The new plan for Canada states that "[w]hatever the approach finally determined, the Government of Canada will work with industry to ensure that covenants with a regulatory or financial backstop are a central element of the Canadian strategy to reduce ... emissions."'ss

Emissions trading is also discussed in the new plan for Canada: "emissions trading is a market mechanism that could provide flexibility for industry in meeting its target." 156 Options being considered involve requiring "companies to have permits to cover their emissions." 57 A large proportion of these would be provided free and, to meet their remaining requirements, companies "could invest in emissions reductions or purchase permits or offsets, or a combination of both." 158 It is stated that "[t]he Government will continue discussions with industry and provincial and territorial governments to ensure the approach taken on emissions intensity is reasonable and the targets achievable."139

\section{Provincial Emissions Trading Legislation}

Each of Alberta, ${ }^{160}$ Manitoba, ${ }^{161}$ Nova Scotia ${ }^{162}$ and British Columbia ${ }^{163}$ and the Yukon Territory ${ }^{164}$ have passed legislation that allows for the creation of an emission trading scheme in various degrees of sophistication. Some, like Alberta, have created rudimentary emission trading principles but do not establish an annual cap on emissions and accordingly, could only be used in conjunction with an emission reduction credit scheme as opposed to a cap in allowance trading scheme. Others, and in particular Nova Scotia, have created a fairly sophisticated emissions trading regime, which includes regulations that have effectively created an emissions cap and allowance trading scheme.

The Alberta legislature is currently considering Bill $37,{ }^{105}$ which the government calls "an action plan for reducing greenhouse gas emissions based on consultations with Albertans." 166 Alberta sets its own emission reduction target in s. 3(1): "The specified gas emission target for Alberta is a reduction by December 31,2020 of specified gas emissions relative to Gross Domestic Product in an amount that is equal to or less than $50 \%$ of 1990 levels." To achieve

\footnotetext{
154 Ibid. at 30.

iss Ibid. at 31 .

is. loid.

157 lbid.

158 lbid.

159 Ibid.

16. Environmental Protection and Enhancement Act, R.S.A. 2000, c. E-12.

1 in Environment Act, S.M. 1987-88, c. 26, as amended.

k.2 Environment Act, S.N.S. 1994-95, c. I.

16) Waste Management Act, R.S.B.C. 1996, c. 482.

lat Environment Act, S.Y. 1991, c. 5.

iss Climate Change and Emissions Managemen Act, 3d Sess., 25th Leg., Alberta, 2003 (assented to 4 December 2003, not yet proclaimed into force as of publication), also found at R.S.A. 2000, c. 16.7. Is, Alberta, "Kyoto Protocol: Our Plan," online: Government of Alberta <www.gov.ab.ca/home/kyoto/ Display.cfm?id=6>.
} 
these reductions, much discretion is left with the Minister to "enter into agreements with representatives of different sectors of the Alberta economy."167

The language of Bill 37 suggests that the Alberta government is preparing for a jurisdictional dispute with the federal government over management of emission reductions. Section 8 gives the Minister authority to enter into agreements with the federal government or with other provincial governments, but explicitly states: "The Minister may not enter into any agreement ... unless the Minister is satisfied that the agreement will be consistent with this Act and with the specified gas emission target for Alberta established by section 3(1)."168

The language in Bill 37 reflects the above discussion relating to division of powers. In the Preamble, the Government of Alberta attempts to characterize the Bill to fit within provincial jurisdiction. In particular, alluding to the federal government's criminal law power, the Preamble states: "WHEREAS atmospheric carbon dioxide and methane are not toxic and are inextricably linked with the management of renewable and non-renewable natural resources, including sinks." In s. 9, it is declared that "[a] sink right is a property right." In light of the very public differences between the Alberta and federal governments with respect to the Kyoto Protocol and emissions reductions, it appears unlikely that the provincial and federal legislation will be reconcilable. This increases the uncertainty for both lawyers and their clients.

\section{E. SUMmaRY}

As noted at the commencement of this article, there is not yet a definitive position on whether one or more domestic emissions trading systems will be implemented in Canada, nor is there a definitive position as to the design features that might be reflected in the systems. The issues raised by emissions trading globally, nationally and locally are significant and complex, and Canada's understanding of the implications of the interplay between these different systems is not far beyond the conceptual stage.

The object of developing one or more workable emissions trading systems is now on a fairly fast track. If they have not already done so, those who will be subject to emissions reduction legislation or voluntary compliance programs need to start to devote the necessary time and resources to educating themselves on various design features of an emissions trading system and how they might impact the way the company does business in the future. 